\title{
Proximodistal Structure of Theta Coordination in the Dorsal Hippocampus of Epileptic Rats
}

\author{
François Laurent, ${ }^{1 \star}$ Jorge R. Brotons-Mas, ${ }^{1 \star}$ Elena Cid, ${ }^{1 \star}$ Diego Lopez-Pigozzi, ${ }^{1}$ Manuel Valero, ${ }^{1}$ Beatriz Gal, ${ }^{1,2}$ \\ and ${ }^{\circ}$ Liset Menendez de la Prida ${ }^{1}$ \\ ${ }^{1}$ Instituto Cajal, CSIC, Madrid 28002, Spain and 2Universidad Europea de Madrid, Villaviciosa de Odón, Madrid 28670, Spain
}

Coherent neuronal activity in the hippocampal-entorhinal circuit is a critical mechanism for episodic memory function, which is typically impaired in temporal lobe epilepsy. To better understand how this mechanism is implemented and degraded in this condition, we used normal and epileptic rats to examine theta activity accompanying active exploration. Assisted by multisite recordings of local field potentials (LFPs) and layer-specific profiling of input pathways, we provide detailed quantification of the proximodistal coherence of theta activity in the dorsal hippocampus of these animals. Normal rats showed stronger coordination between the temporoammonic and perforant entorhinal inputs (measured from lamina-specific current source density signals) at proximal locations, i.e., closer to CA3; while epileptic rats exhibited stronger interactions at distal locations, i.e., closer to subiculum. This opposing trend in epileptic rats was associated with the reorganization of the temporoammonic and perforant pathways that accompany hippocampal sclerosis, the pathological hallmark of this disease. In addition to this connectivity constraint, we discovered that the appropriate timing between entorhinal inputs arriving over several theta cycles at the proximal and distal ends of the dorsal hippocampus was impaired in epileptic rats. Computational reconstruction of LFP signals predicted that restoring timing variability has a major impact on repairing theta coherence. This manipulation, when tested pharmacologically via systemic administration of group III mGluR antagonists, successfully reestablished theta coordination of LFPs in epileptic rats. Thus, proximodistal organization of entorhinal inputs is instrumental in temporal lobe physiology and a candidate mechanism to study cognitive comorbidities of temporal lobe epilepsy.

Key words: coherence; multisite silicon probes; proximodistal; theta oscillations

\section{Introduction}

Deficits of episodic memory occur in neurological conditions like Alzheimer's disease (Maguire and Frith, 2003) and temporal lobe epilepsy (TLE; Helmstaedter, 2002), known to specifically affect temporal lobe circuits (Gómez-Isla et al., 1996; Schwarcz and Witter, 2002; Di Paola et al., 2007). While the medial entorhinal cortex (MEC) hosts grid, border, and head-direction cells with spatial firing specificities (Sargolini et al., 2006), the lateral entorhinal cortex (LEC) comprises neurons encoding both nonspatial and complex spatial information (Young et al., 1997; Hargreaves et al., 2005; Deshmukh and Knierim, 2011). MEC and LEC inputs converge into the hippocampus, which reciprocally project to the parahippocampal cortex (Tamamaki and Nojyo, 1995; Witter et

\footnotetext{
Received Oct. 17, 2014; revised Jan. 16, 2015; accepted Feb. 10, 2015.

Author contributions: L.M.d.I.P. designed research; F.L., J.R.B.-M., E.C., D.L.P., M.V., and B.G. performed research; F.L., J.R.B.-M., E.C., and L.M.d.I.P. analyzed data; L.M.d.I.P. wrote the paper.

This work was supported by grants from the Spanish Ministerio de Economía y Competitividad (BFU2009-07989 and BFU2012-37156-C03-01) and the Intramural CSIC Grant 201220E084. E.C. is a JAE-Doc fellow from the CSIC JAE Program cofunded by the European Social Fund. We thank Shigeyoshi Itohara from RIKEN, Japan, for the generous gift of netrinG1 and netrinG2 antibodies, and Guglielmo Foffani for discussion, comments on this manuscript, and help with statistical analysis. We also thank Rafael Gutierrez, Xavier Leinekugel, and Bryan Strange for comments on this manuscript.

* F.L., J.R.B.-M., and E.C. contributed equally to this work.

Correspondence should be addressed to Liset Menendez de la Prida, Instituto Cajal, CSIC, Ave Doctor Arce, 37, Madrid 28002,Spain. E-mail: Imprida@cajal.csic.es.

J. R. Brotons-Mas' present address: Instituto de Neurociencias, Universidad Miguel Hernández, Alicante, Spain. DOI:10.1523/JNEUROSCI.4297-14.2015

Copyright $\odot 2015$ the authors $\quad 0270-6474 / 15 / 354760-16 \$ 15.00 / 0$
}

al., 2000; Naber et al., 2001). Hence, firing of hippocampal neurons reflects a combinatorial representation of spatial (O'Keefe and Nadel, 1978; Komorowski et al., 2009; Neunuebel and Knierim, 2012) and temporal information (Mankin et al., 2012; Kraus et al., 2013; Kitamura et al., 2014) together with recent experience (Frank et al., 2000; Wood et al., 2000). This neuronal coding is tightly organized within a timescale defined by ongoing oscillations (Buzsáki and Moser, 2013; Lisman and Jensen, 2013), including the hippocampal theta rhythm (Bland and Oddie, 2001; Hasselmo et al., 2002; Huxter et al., 2008; Mizuseki et al., 2009; Easton et al., 2012; Gupta et al., 2012). The ability to associate/dissociate items and locations within a particular temporal framework is instrumental to episodic memory function and presumably relies on this intricate organization of the temporal lobe (Eichenbaum et al., 1999; Aggleton and Pearce, 2001; Burgess et al., 2002).

Recently, we showed that TLE rats with specific deficits of the integrated "what-where-when" component of episodic-like memory exhibited theta oscillations of reduced power and coherence (Inostroza et al., 2013). These distinct spectral features reflect dynamic variations of the underlying cellular processes depending on cognitive demands, speed, and exploratory experience (Wyble et al., 2004; Benchenane et al., 2010; Penley et al., 2013; Wells et al., 2013; Igarashi et al., 2014). In TLE rats, decreased theta coherence was concentrated between LFP signals at the stratum lacunosum moleculare (SLM) and the molecular 
layer of the DG (Inostroza et al., 2013), which receives direct entorhinal inputs. The temporoammonic pathway emerging from layer III MEC and LEC targets SLM in a proximodistal arrangement (Witter et al., 2000) and abundantly expresses presynaptic mGluRs, mostly mGluR7 and mGluR2 (Shigemoto et al., 1997). The layer II perforant pathway terminating at DG segregates at the outer (MLo) and middle molecular layer (MLm), depending on their lateral or medial origin in the entorhinal cortex (Naber et al., 2001; Witter, 2007) and expresses presynaptic mGluR8 and mGluR2 (Macek et al., 1996; Shigemoto et al., 1997). Given the role of this intricate organization of temporal lobe circuits in theta activity and episodic memory, we sought to better understand the proximodistal structure of theta coherence disruption in TLE rats exhibiting episodic-like memory deficits.

To this purpose, we have used the specific expression of cellsurface proteins netrinG1 and G2 in the lateral and medial branches of entorhinal input pathways (Nishimura-Akiyoshi et al., 2007), in combination with electrophysiological profiling, to examine theta activity in the dorsal hippocampus of normal and epileptic-behaving rats. We demonstrate that proximodistal disruption of theta coherence in TLE is intimately related to the reorganization of the temporoammonic/perforant pathways and to appropriate timing coordination between these entorhinal inputs.

\section{Materials and Methods}

Animals. Adult, male Wistar rats (180-200 g) were housed individually and assigned randomly to the control or epileptic groups. Rats in the epileptic group received multiple systemic injections of kainate $(5 \mathrm{mg} / \mathrm{kg}$, i.p.) at hourly intervals until they reached status epilepticus. They were injected $1 \mathrm{~h}$ later with diazepam $(4 \mathrm{mg} / \mathrm{kg}$, i.p) to stop convulsions. Epileptic animals received intraperitoneal injections of $2.5 \mathrm{ml} 5 \%$ dextrose in saline and their diet was supplemented with fruit and powder milk during the following 2-3 d. Some control rats were injected with saline instead of kainate and received treatments similar to epileptic animals $(n=5)$. Untreated normal rats $(n=8)$ completed the control group, since no differences between them and saline-injected animals were detected in indices of theta coherence and power. A total of $n=13$ normal and $n=13$ epileptic rats was used in the study. Procedures met the European guidelines for animal experiments (86/609/EEC) and were approved by the ethics committee of the Instituto Cajal and CSIC. All experiments started 8 weeks post status when rats already exhibited recurrent seizures and were thus in the chronic phase of the disease. As we previously reported, in epileptic rats periods of normal-like LFP activity were intermixed with periods dominated by epileptiform events defined as convulsive or subclinical seizures and interictal discharges (Inostroza et al., 2013, their Figure 3). To exclude effects of ictal and interictal activity we focused only in sessions free from any sign of epileptiform events as judged from LFP recordings. Importantly, sessions recorded within $2 \mathrm{~h}$ before and after a convulsive seizure were excluded from the analysis.

Electrophysiological recordings. For electrophysiological studies, a total of $n=10$ control and $n=9$ epileptic rats was used. Animals were implanted at least 6-7 weeks post status (or equivalently in the control group) to guarantee electrophysiological recordings were all obtained after 8 weeks post status once animals recovered from surgery. Sixteenchannel silicon probes (NeuroNexus; 0.3-1.2 Mohm site impedance; interelectrode distance $100 \mu \mathrm{m}$ ) were implanted either fixed or mounted on an adjustable microdrive (either custom-made or the nDrive; NeuroNexus). For electrode implantation, rats were anesthetized with isoflurane (1.5-2\%) in oxygen (30\%) and continuously monitored with an oximeter (MouseOx; Starr Life Sciences). Implantation coordinates ranged from -3.9 to $-6 \mathrm{~mm}$ posterior to bregma and between 2 and 5 $\mathrm{mm}$ from the midline, according to Paxino's atlas (Paxinos and Watson, 2005). Probes were implanted perpendicular to the skull surface (i.e., no head angle). Two screws served as a reference and ground at the occipital region. After recovering from surgery (acute treatment including enrofloxacin $10 \mathrm{mg} / \mathrm{kg}$, s.c.; methylprednisolone $10 \mathrm{mg} / \mathrm{kg}$, i.p.; and buprenorphine $0.05 \mathrm{mg} / \mathrm{kg}$, s.c.), electrophysiological recordings were obtained using a multichannel amplifier (Dacq system; Axona) and headstages of unity gain. LFP signals were amplified by 400 and recorded at $4800 \mathrm{~Hz} / 12$-bit precision in a $1-2400 \mathrm{~Hz}$ frequency band after analog filter. The rat's $x$ and $y$ position was recorded with an infrared LED and acquired at $50 \mathrm{~Hz}$ with resolution of 300 pixels/m. Hippocampal activity was monitored during several behavioral conditions (walking, running, immobility, and sleep). Only data from awake periods were included in the current analysis. Experiments began between 2 and $7 \mathrm{~d}$ after surgery when animals had recovered and theta power and coherence values stabilized (i.e., there were no major differences in spectral values between consecutive days for a given animal). Recordings were obtained daily between 2 and 7 pm over 1-3 weeks while the animals performed either habituation to the open field or object-recognition tasks (up to three sessions of 3 min every day, typically from Monday to Friday). Details of behavioral tasks were described previously (Inostroza et al., 2013).

Pharmacological interventions. The effect of group III metabotropic receptor antagonist CPPG $(2 \mathrm{mg} / \mathrm{kg})$ and agonist L-AP4 (5-10 mg/kg) on indices of theta power and coordination was analyzed $1 \mathrm{~h}$ after a single intraperitoneal injection in $n=6$ epileptic rats. The pharmacological effect on spectral indices was evaluated by comparing with data obtained from an immediately previous session ( $>1 \mathrm{~h}$ predrug). The effect of these drugs was consistent when tested in several sessions (days) in a number of animals ( $n=3$ CPPG, $n=1$ L-AP4). Drugs (from Tocris Bioscience) were dissolved in saline (vehicle). The potential effect of vehicle injections was evaluated in a subset of epileptic animals $(n=3)$. All animals were first habituated to intraperitoneal injections of saline to prevent side effects in electrophysiology and behavior, i.e., mild stress is induced by these manipulations.

Immunostaining, probe localization, and layer profiling. After completing recordings (from 8 to 11 weeks post status), implanted rats ( $n=10$ control, $n=9$ epileptic) were perfused intracardially with $30 \mathrm{ml}$ of PBS $0.1 \mathrm{M}, \mathrm{pH} 7.3$, with $0.2 \%$ heparin, followed by $200 \mathrm{ml}$ of $4 \%$ paraformaldehyde. Brains were removed and coronal sections $(20 \mu \mathrm{m})$ were cut on a vibratome. Immunohistochemistry, using a monoclonal anti-NeuN antibody (1:1000; Bachem), polyclonal anti-netrinG1 (1:10), and antinetrinG2 (1:100; both a gift from S. Itohara), was performed on floating sections using the biotin-avidin-peroxidase method. NeuN was evaluated in the section containing the probe track, and netrinG1 and netrinG2 were evaluated in adjacent sections. Images were taken with a Leica DFC295 camera coupled to a stereomicroscope (S8APO; Leica).

Probe localization in stereotaxic coordinates was inferred using the NeuN section of the whole hemisphere to identify anatomical landmarks in the Paxino's atlas and to assign each section to a particular bregma level (anteroposterior coordinate; Paxinos and Watson, 2005). The mediolateral coordinate was estimated from the projection of the probe track at the corresponding bregma section. The intermediate hippocampus was defined at half-length of CA1 layer in each section. Proximal CA1 was defined from the intermediate line to the limit with CA2 identified as the typical increase of the cell-body layer. Distal CA1 was defined from the intermediate line to the limit with the subiculum, identified at the point where CA1 cell layer shows cell dispersion at the stratum oriens.

For entorhinal pathway profiling, we exploited the differential specificity of the membrane-anchored proteins of the UNC-6/netrin family, netrinG1 and G2, for the lateral and medial temporoammonic and perforant pathways (Nishimura-Akiyoshi et al., 2007). NetrinG1 immunoreactivity is restricted to the terminal layers of the temporoammonic pathway in CA1 (SLM) and to the lateral perforant pathway in DG (MLo), whereas netrinG2 is restricted to the terminal layers of the medial perforant path (MLm). Sections stained against NeuN, netrinG1, and netrinG2 were combined to identify SLM, MLo, and MLm. The position of each recording channel in the different layers was determined using both electrophysiological and histological information. Cell-body layers [CA1 stratum pyramidale (SP) and the granule cell (GC)] were identified in NeuN sections and assigned to the corresponding channels in the 16-channel linear array. This process helped us to calibrate images given the known interelectrode distance $(100 \mu \mathrm{m})$. Sinks and sources of rele- 
vant electrophysiological events, i.e., sharp waves (SPW; Ylinen et al., 1995) and dentate spikes of types 1 and 2 (DS1 and DS2; Bragin et al., 1995), were used to further assign channels to layers identified in calibrated sections. Channels at SLM, MLo, and MLm were identified using information from CSD data from DS1 and DS2 events and netrinG1 and G2 immunostaining. Recording channels at the stratum radiatum (SR) were identified using information from $\mathrm{NeuN}$ and the netrinG1-positive SLM band together with information from the SPW sink. Channels at the inner ML (MLi) were identified using information from the DS2 sinks and sources together with information from netrinG2 and NeuN stainings.

For quantification of the temporoammonic and perforant pathways, netrin G1 and G2 sections ( $20 \mu \mathrm{m})$ were used to measure the band thickness at proximal and distal locations, using images at $10 \times$ magnification and Image (v1.47t; NIH). To this purpose, the proximal and distal ends of the dorsal hippocampus ( 1 section per animal, adjacent to the probe track) were identified. The thickness of each band at distal and proximal locations was measured from four equally distributed positions, and a mean thickness per band per section was calculated. Bands were defined based on anatomical limits (i.e., hippocampal fissure for SLM and MLo) and the clear-cut immunoreactivity limits to netrinG1 (for SLM) and G2 (for MLm). The less clear limit at the boundary between MLo and MLm was defined at the point where immunoreactivity was below $\sim 75 \%$ of maximal intensity per section. Only the upper blade of the DG is considered for analysis. Data are reported as mean \pm SD and analyzed with two-way ANOVA with groups and layers as factors and post hoc Student's $t$ tests.

Entorhinal cell counting. To quantify neuronal loss in different layers of the lateral and medial entorhinal cortices we prepared horizontal sections $(50 \mu \mathrm{m})$ from a different cohort of animals $(n=3$ control, $n=4$ epileptic). Rats were perfused with $0.2 \%$ heparin in PBS $(0.1 \mathrm{M})$, followed by $4 \%$ paraformaldehyde, and the tissue processed as explained above for NeuN immunostaining. Sections were identified at three different dorsoventral levels (A, dorsal; B, intermediate; and C, ventral) using information from the horizontal brain atlas (Paxinos and Watson, 2005, their Fig. 4D). Level A was defined at approximately $-4.7 \mathrm{~mm}$ ventral to bregma, level B was defined at $-5.6 \mathrm{~mm}$, and level $\mathrm{C}$ was defined at -7.1 $\mathrm{mm}$. One section per level and rat was identified using anatomical landmarks. At each level, the external limits of entorhinal cortex were identified from the lamina dissecans. Since the limit between MEC and LEC varies along the dorsoventral axis and could not be consistently identified, we focused at the medial and the lateral extremes of the entorhinal cortex to identify MEC and LEC cells, respectively. To estimate cell density in different layers, the width of a rectangular area of $200 \mu \mathrm{m}$ length was adjusted to the thickness of layer II and layer III, using the Stereo Investigator (version 9.04; MBF Bioscience) coupled to a Nikon microscope with $20 \times$ lens (Nikon Eclipse Ei80). All NeuN-positive cells in these areas were counted along the $50 \mu \mathrm{m}$ in the $z$-axis. At the ventral level, layer II cells at LEC appear spatially segregated (fan cells, at the most superficial locations and deepest pyramidal cells; Tahvildari and Alonso, 2005) and they were counted separately. Cell count was divided by the area and expressed as neurons per $\mathrm{mm}^{2}$ (mean $\pm \mathrm{SD}$ ). Between groups statistical differences were evaluated using a two-way ANOVA for each dorsoventral level with groups and layers as factors and confirmed with $t$ tests.

Spectral analysis of electrophysiological signals. LFP and CSD signals were analyzed using routines written in MATLAB (MathWorks, v.10b) and/or Octave (www.octave.org). CSD signals were calculated from LFP data using the second spatial derivative at $100 \mu \mathrm{m}$ resolution. Defective sites were reconstructed by interpolation for illustration purposes only. Smoothing was only applied for visualization. Defective sites and smoothed signals were never used for analysis. Data segments (1 s, nonoverlapping) free of artifacts and with continuous theta activity were identified from different recording sessions using spectral criteria based on the presence of a dominant power peak at the theta band as compared with all frequency bands in each given session. The spectral power was given in decibels $(10 . \log 10)$ and calculated using a Hamming window and the fast Fourier transform at $1 \mathrm{~Hz}$ resolution. Theta power was estimated from the spectrum (area in the $4-12 \mathrm{~Hz}$ band) for each data segment and averaged across all segments in a given session (300 s)]. Pairwise theta coherence was defined from the cross-spectral power densities at the peak frequency in the $4-12 \mathrm{~Hz}$ range (Franaszczuk et al., $1985)$ at $1 \mathrm{~Hz}$ resolution. Note that this coherence measurement does not depend on power variations of the original signals at the corresponding time resolution ( $1 \mathrm{~s})$.

Spectral data were evaluated in different layers using channel assignment as described above. Between-group theta power differences were evaluated using ANOVA with group (control/epileptic and predrug/ drug), location (proximal/distal), and layers as factors. The influence of running speed on spectral indices was assessed by a two-way ANOVA for groups (control/epileptic) and speed (12 levels) as evaluated from histogram distributions ( $5 \mathrm{~cm} / \mathrm{s}$ bins; Inostroza et al., 2013, their Fig. 5F). Post hoc comparisons were performed using Welch's tests. For pairwise theta coherence, we estimated the coupling between every possible pair of channels corresponding to each given layer and averaged data across the different pairs to evaluate within- and between-layer coupling. Withinlayer coherence was estimated in animals with at least two channels per layer. Pairwise theta coherence was represented in a matrix and betweengroup differences were evaluated using two-way ANOVA (for groups and layers). Results from statistical Welch's $t$ tests were represented in a contrast matrix as $-\log 10$ of $p$ values (only for those values $<0.05$ ) and Bonferroni corrected. Data are reported as mean $\pm 95 \%$ confidence interval.

Analysis of intercycle variability. Given the link between the spectral coherence between channels and the consistency of oscillatory cycles, we aimed to evaluate the intercycle variability of CSD and LFP theta oscillations. Artifact-free epochs were divided in $2 \mathrm{~s}$ windows with $50 \%$ overlap, and theta cycles were individually detected within each window and channel. For cycle detection, LFP and CSD signals were treated similarly. To this purpose, signals were first multi-bandpass filtered from 1 to 500 $\mathrm{Hz}$ to remove at the same time the $50 \mathrm{~Hz}$ component and its harmonics and, subsequently, smoothed with a moving Hanning window $(50 \mathrm{~ms})$ to give a preprocessed clean signal. In a first step (predetection), theta cycles were approximately identified by refiltering the previous signal in the $6-10 \mathrm{~Hz}$ band and detecting positive peaks (crests). Then, negative peaks (troughs) between pairs of previously detected crests were detected in the preprocessed signal. Crests were redetected similarly (one crest between two successive troughs). This strategy was adopted to preserve the characteristics of typically asymmetric theta waveforms. Some detected peaks were rejected based on the following criteria: an intercrest (respectively, intertrough) interval $<67 \mathrm{~ms}$ or $>200 \mathrm{~ms}$ and absolute amplitude (crest to trough) below the first quartile of the amplitude distribution from the whole recording session. Finally, we considered only troughs surrounded by two crests before and after (to quantify waveform asymmetry). Note that, because of the predetection step that involves windowing and filtering, cycles at the beginning and end of a given segment were always missed, hence the need for at least a $2 \mathrm{~s}$ window.

To analyze intercycle variability between two channels, cycles were first detected in these two channels independently. Then, cycles in the reference channel were used to look for matching cycles in the channel of interest. Both the timing and amplitude of each detected trough and the surrounding crests were used to estimate the variability of waveform within and between channels. Waveform asymmetry in a given channel was measured as $\left(\right.$ Slope $_{\text {crest }}+$ Slope $\left._{\text {trough }}\right) /\left(\right.$ Slope $_{\text {crest }}-$ Slope $\left._{\text {trough }}\right)$, where the slope refers to the descending and ascending part of the cycle. Variability of waveform asymmetry was estimated as the SD of the asymmetry ratio of all cycles in a given channel. Phases between channels were estimated from the time lag between troughs of matching cycles and the jitter was defined as the SD (in milliseconds). All measurements were estimated for each $2 \mathrm{~s}$ window and then averaged across the entire session (300 s). Data are reported as mean $\pm 95 \%$ confidence interval and analyzed with a two-way ANOVA for groups and layers.

Computational correction of waveform and jitter variability. We tested the effect of restoring either CSD cycle waveform or jittering in the spectral organization of LFP signals in epileptic rats. To this purpose we designed a correction procedure based on LFP reconstruction. First, CSD theta cycles detected in a channel at the reference layer were matched to the corresponding cycles in the channel at the layer to be corrected. Note 
that this procedure focuses only in matching cycles at the two layers and therefore it is always a pairwise correction. To correct for waveform variability, the average cycle waveform was first estimated from all detected cycles of the entire session. Then, each individual cycle in the corrected layer (125 ms) was replaced by the amplitude-adjusted mean waveform cycle thus neglecting individual variability while preserving temporal variability in $2 \mathrm{~s}$ windows. Note that the amplitude was adjusted on a cycle-by-cycle basis to preserve theta power. To prevent bound effects, the corrected signal was merged with the original one using a Hanning window as a mask: $s_{\text {corrected }}(t)=s_{\text {average }}(t) \cdot h(t)+s_{\text {old }}(t) \cdot(1-$ $h(t))$, where $s(t)$ denotes the signal and $h(t)$ the corresponding Hanning coefficient. Correction for jitter was performed by shifting each detected cycle $(125 \mathrm{~ms})$ in the corrected channel so that they featured a constant (or variability-controlled) lag with the corresponding cycles at the reference channel. Shifting a cycle consisted of inserting the cycle fragment (i.e., the newly timed cycle) at the desired time instant. Similarly to waveform correction, this was performed using a Hanning window as a mask. This procedure did not perfectly remove fluctuations around the original cycle, which contributed as noise. Finally, LFP signals were estimated from corrected CSD signals in each window using the following equation (Pettersen et al., 2006):

$$
\operatorname{LFP}_{i}^{\prime}=1 /(2 \sigma) \cdot \Sigma_{j}\left[\left(\sqrt{ }\left((i-j)^{2}+R^{2}\right)-|i-j|\right) \cdot \operatorname{CSD}_{j}\right]
$$

where $i$ and $j$ refer to channels, $\sigma=0.3(\mathrm{~S} / \mathrm{m})$ is the conductivity of the medium, and $R=7$ is a factor. The value for $R$ can be interpreted as integrating the CSD in a cylinder of radius $700 \mu \mathrm{m}$ around the axis of the probe. This value was parametrically determined (range for $R: 1-10)$ to minimize differences between coherence matrices from the original and reconstructed LFP signals.

The effect of correction was evaluated by comparing coherence from reconstructed LFP only, with and without correction. Data from $n=3$ rats with sufficient numbers of cycles in SLM, MLo, and MLm were used. Statistical differences were evaluated over $Z$-scores.

\section{Results}

Using 16-channel linear array probes with $100 \mu \mathrm{m}$ interspaced contacts, we recorded LFP signals from the dorsal hippocampus of normal $(n=10)$ and TLE rats $(n=9)$ while they were engaged in active exploration of the open field and objects in sessions of 3 min each. Only one session per rat was used for analysis. Seizurerelated effects in TLE rats were excluded by focusing our study only in periods lacking any sign of epileptiform activity (see Materials and Methods).

\section{Layer-specific profiling of theta coordination in TLE versus control rats}

Theta oscillations recorded in normal (Fig. $1 A$ ) and epileptic rats (Fig. $1 B$ ) exhibited the typical depth spatial profile along the CA1-DG axis, including similar phase reversal of theta cycles (Fig. 1C,E, leftmost plot, black traces; Montgomery et al., 2009). Analysis of associated CSD signals (Fig. 1C,E, sinks are blue, sources are red) revealed the heterogeneous nature of different inputs arriving over each theta cycle (Brankack et al., 1993). To specifically quantify contribution across layers, i.e., SP, SR, SLM, ML, and GC layers, and to facilitate comparison between animals, we identified different hippocampal strata aided by electrophysiological and immunohistochemical profiling.

To this purpose, for each animal we isolated individual SPW and dentate spikes DS1 and DS2 (Bragin et al., 1995; Ylinen et al., 1995) known to have a clear pattern of CSD sinks and sources at specific layers (Fig. 1C,E; data from the same animal as shown for theta cycles). This electrophysiological analysis was combined with postmortem immunostaining against the neuronal marker NeuN to identify cellular layers around the probe track and against netrinG1 and G2 to specifically separate temporoam- monic and perforant pathways (Fig. 1D,F; see Materials and Methods). Sections stained for netrinG1 and G2 were superimposed around the probe track (stained with $\mathrm{NeuN}$ ) to assign channels to specific layers, together with CSD information from SPW, DS1, and DS2 events. The netrinG1-positive temporoammonic pathway originates from layer III neurons of the entorhinal cortex and terminates at SLM. The lateral (netrinG1-positive) and medial (netrinG2-positive) perforant pathways arising from layer II neurons of LEC and MEC terminate at MLo and MLm, respectively (Nishimura-Akiyoshi et al., 2007; Witter, 2007). Channels at MLi were identified using combined information from the limits of DS2 sinks together with netrinG2 and NeuN immunostaining.

Using this information, we then estimated theta coherence between all channels along the electrode array against a reference channel at any given layer. Figure $1, G$ and $H$, shows the cases for one reference channel at SLM (blue) and MLm (green) in recordings shown in Fig. $1 A$ and $B$. Theta coherence between layers was evaluated by collecting all potential pairwise estimations involving channels at each layer. Data were represented in a matrix form (Fig. $1 G^{\prime}, H^{\prime}$ ) to better evaluate both within-layer (at the matrix diagonal) and between-layer coherence (nondiagonal elements of the matrix). Note that in each individual matrix every element reflects the mean value of theta coherence between all channel pairs in the corresponding layers. In the example shown in Fig. $1 G$, coherence between the two recording sites at MLm contributed to the within-MLm coherence in the matrix, while all pairwise estimations (four) between the two MLm and the two SLM sites contributed to a mean MLm-SLM coherence (Fig. $1 G^{\prime}$, arrows). When only one channel was available in a given layer no within-layer coherence could be reported (Fig. $1 G^{\prime}, H^{\prime}$, SP). Note that by definition, our coherence measurement is symmetric (Fig. $1 H^{\prime}$, arrows). We used this representation to look at group differences of theta coherence.

\section{Disruption of theta coordination in TLE is layer specific}

We next analyzed differences in theta coherence obtained from LFP signals in normal $(n=10)$ and epileptic rats $(n=9)$. Mean group matrices were calculated by averaging individual matrices obtained from different animals (Fig. 2A). We similarly estimated theta coherence from CSD signals (Fig. $2 B$ ) to exclude volume conduction effects and to directly look at the multiple generators of LFP activity (Mitzdorf, 1985; Montgomery et al., 2009).

A two-way ANOVA of LFP theta coherence values (transformed as $\log 10$ ) with groups (control and epileptic) and pairs of layers (28) as factors indicated an effect for group $\left(F_{(1391)}=21.9\right.$, $p<0.0001)$, layers $\left(F_{(27,391)}=4.86, p<0.0001\right)$, and their interaction $\left(F_{(27,391)}=1.84, p=0.0071\right)$. Running speed did not account for these spectral differences (mean control: $13 \pm 2 \mathrm{~cm} / \mathrm{s}$; epileptic: $11 \pm 4 \mathrm{~cm} / \mathrm{s} ; p=0.1141$; similar speed distribution: $\left.F_{(1192)}=1.3, p=0.2177\right)$

We evaluated the contribution of each pair of layers to the group difference using Welch's $t$ tests and represented them in a matrix form (contrast matrix) as $-\log _{10}$ of $p$ value (Fig. $2 A$, grayscale). We observed that reduction of LFP theta coherence in TLE rats tended to concentrate at the SLM-ML cluster and within MLm (Fig. 2A; only values $<0.05$ are represented), consistent with our previous LFP data (Inostroza et al., 2013). Decreased coherence in epileptic versus normal rats was also clear for CSD signals $\left(F_{(1360)}=7.2, p=0.0073\right.$ for group; $F_{(27,360)}=2.5, p<$ 0.0001 for layers), suggesting that local cellular processes were involved. Indeed, the typical cluster of interaction between SLM and ML strata (MLo, MLm, and MLi) visible in the control ma- 
A
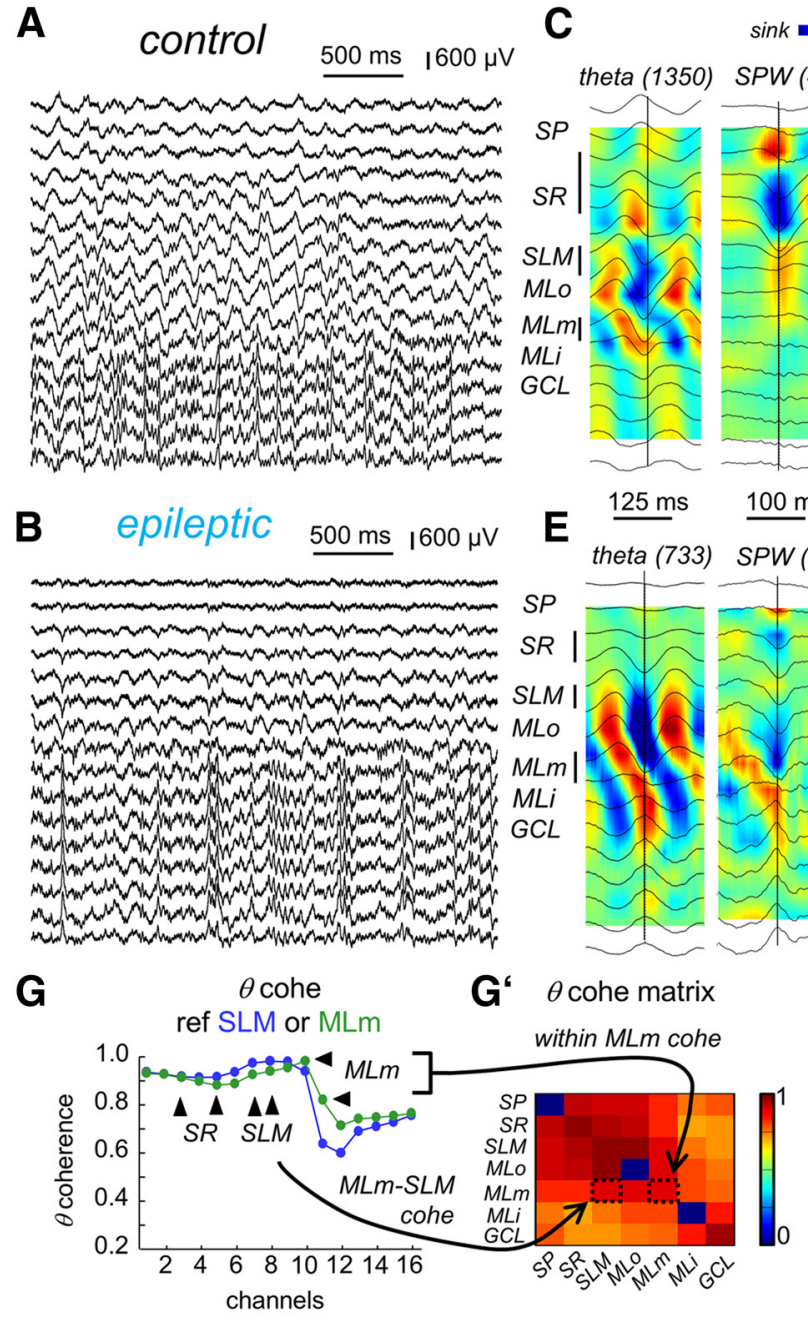

C

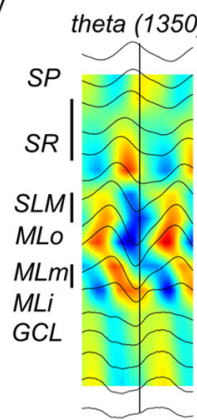

$\mathrm{E}$

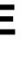

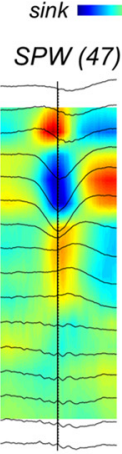

$100 \mathrm{~ms}$ source

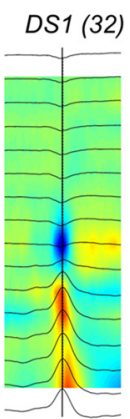

$100 \mathrm{~ms}$

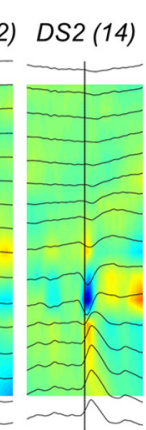

D netrinG1 netrinG2 NeuN
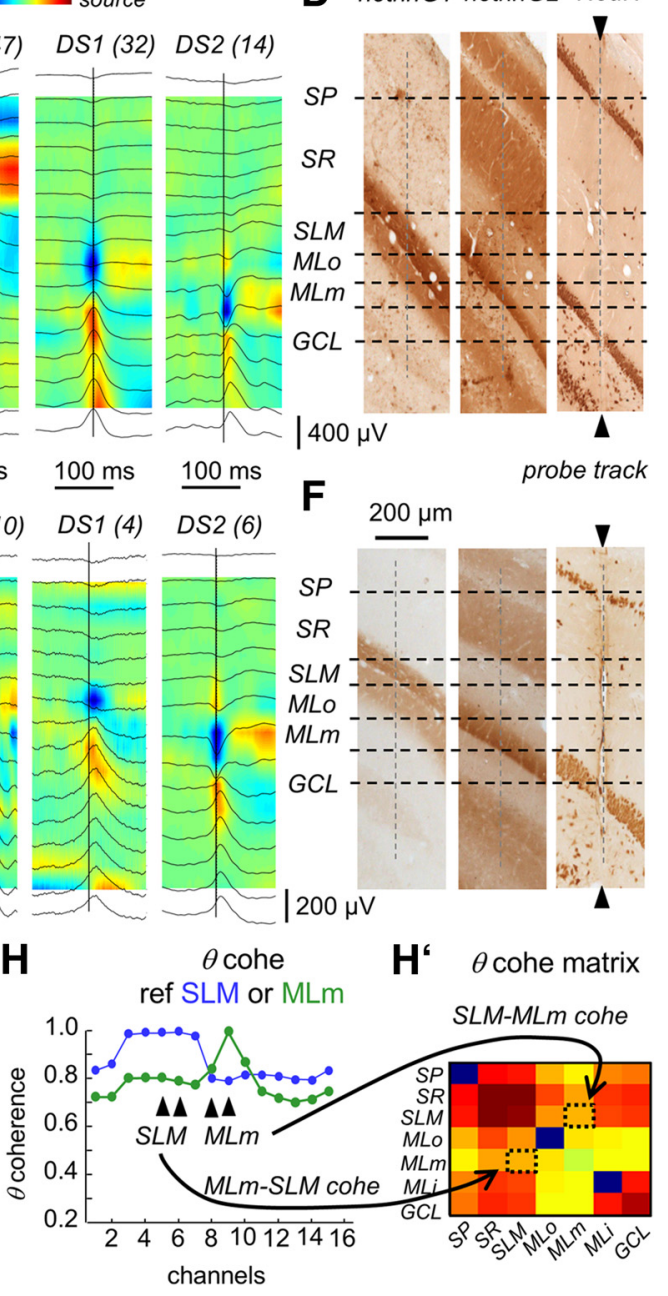

Figure 1. Layer-specific profiling of theta coordination in the dorsal hippocampus. $\boldsymbol{A}$, Representative 16-channel recordings of LFPs during exploratory theta activity in a normal rat. $\boldsymbol{B}$, Representative LFP recordings from an epileptic rat engaged in active exploration. Recordings were obtained in periods between seizures, in the absence of interictal spikes and other types of epileptiform events. C, A combination of electrophysiological and immunostaining tools was used to identify recording sites and hippocampal layers. Averaged LFP (black traces) and CSD signals (color map: sinks are blue, sources are red) during theta, SPW, and DS1 and DS2 were used to identify specific layers. Data from the control rat shown in $A$. Numbers in parenthesis indicate the number of events of each type used. $\boldsymbol{D}$, Postmortem immunostaining against netrinG1 and $\mathrm{G} 2$ together with the neuronal marker NeuN aided to assign recording channels to specific hippocampal lamina. Images from the control rat shown in $\boldsymbol{A}$ and $\boldsymbol{C}$. $\boldsymbol{E}, \boldsymbol{F}$, Same as in $\boldsymbol{C}$ and $\boldsymbol{D}$ for the epileptic rat shown in $\boldsymbol{B}$. $\boldsymbol{G}$, Laminar profile of theta coherence (cohe; $4-12 \mathrm{~Hz}$ ) between all channels and a reference channel at the SLM (blue) or at the MLm (green) for the normal rat shown in $\boldsymbol{A}$. $\boldsymbol{G}^{\prime}$, Layer-based theta coherence matrix depicting pairwise estimation of theta coherence between (nondiagonal elements) and within layers (diagonal elements) for the control rat shown in $\boldsymbol{A}$. Arrows from $\mathbf{G}$ to $\mathbf{G}^{\prime}$ indicate how coherence values represented in the matrix were obtained from pairwise estimations between recording sites. $\boldsymbol{H}_{,} \boldsymbol{H}^{\prime}$, Same as in $\boldsymbol{G}$ and $\boldsymbol{G}^{\prime}$ for the epileptic rat shown in $\boldsymbol{B}$. Arrows from $\boldsymbol{H}$ to $\boldsymbol{H}^{\prime}$ indicate symmetric coherence values between SLM and MLm. $G C L$, granule cell layer.

trix was impaired in TLE, but the contrast matrix failed to detect statistical differences except for MLm, probably reflecting large variability in the trends (Fig. 2B). Note that even though some of these values would not survive a conservative Bonferroni correction $[2.75=-\log 10(0.05 / 28)]$, they clustered in adjacent hippocampal layers (especially for LFP signals), which is unlikely to happen by chance. These changes of theta coherence in TLE rats at the border between SLM and ML layers pointed to impaired coordination between temporoammonic (i.e., to SLM) and perforant inputs (to MLo and MLm) as a potential underlying mechanism.

\section{Different expression of theta coordination along the proximodistal axis}

We then examined the possibility that variability of theta coherence between CSD signals from SLM, MLo, MLm, and MLi could explain LFP difference between normal and epileptic rats. Given the different proximodistal arrangement of the temporoam- monic and perforant pathways (i.e., from CA3 to subiculum; Witter, 2007; Fig. 3A), we considered the implanting coordinates of each animal to account for variability caused by topographic factors. Implanting locations were classified as proximal (i.e., close to CA3; $n=5$ control, $n=5$ epileptic) and distal (i.e., close to the subiculum, $n=5, n=4$ epileptic).

Representing data from each animal in the corresponding coordinate suggested proximodistal differences of theta coherence among SLM-MLo, SLM-MLm, and MLo-MLm (Fig. 3B, coherence values are represented as scaled dots, see scale at right). For LFP signals, a three-way ANOVA for groups, implanting location (proximal/distal), and pairs of layers showed significant effect for group $\left(F_{(1,45)}=15.9, p=0.0002\right)$ and location $\left(F_{(1,45)}=7.7, p=\right.$ 0.0033 ) but not for layers or interactions. Nonetheless, a two-way ANOVA for each pair of layers showed that group differences of theta coherence concentrated at SLM-MLm $\left(F_{(1,14)}=12.3, p=\right.$ $0.0034)$ and MLo-MLm $\left(F_{(1,13)}=12.1, p=0.0041 ;\right.$ Fig. $\left.3 C\right)$. No speed differences between animals recorded at distal and proxi- 
A LFP layer-based $\theta$ cohe

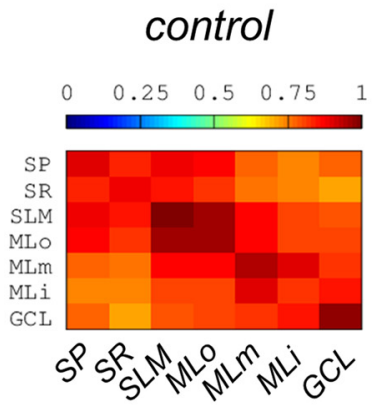

\section{-log(p-value)}

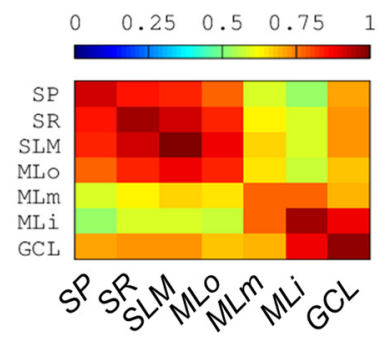

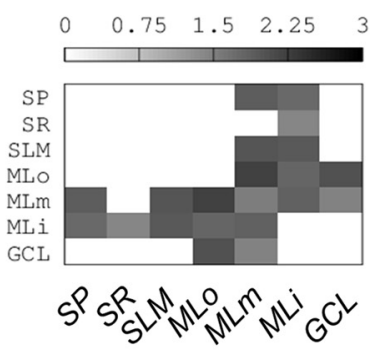

\section{B CSD layer-based $\theta$ cohe}
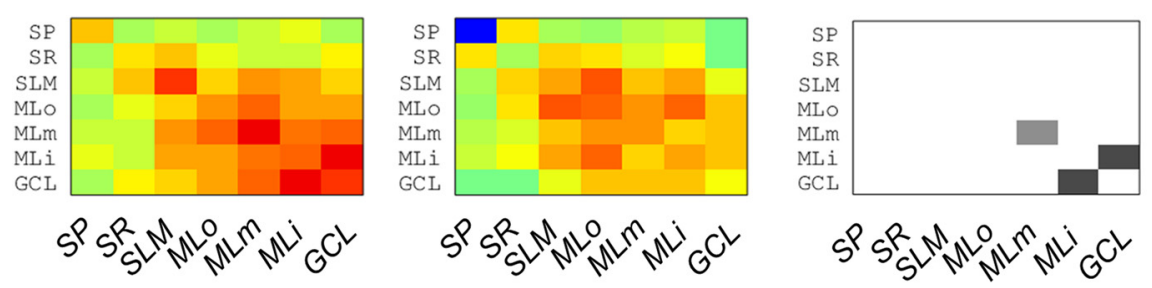

Figure 2. Group layer-based theta coherence (cohe) and statistical contrast matrices. $\boldsymbol{A}$, Mean group layer-based group coherence matrices for LFP signals recorded during exploratory theta activity, together with the contrast matrix (Welch's test) showing $p$ values as $-\log 10$. Only significant $p$ values $(<0.05)$ are depicted. The level for Bonferroni correction is at $2.75=-\log 10(0.05 /$ 28). Data from $n=10$ control and $n=9$ epileptic rats. $\boldsymbol{B}$, Same as in $\boldsymbol{A}$ for CSD signals. GCL, granule cell layer.

at proximal sites $\left(F_{(1,54)}=4.9, p=0.0314\right.$; Fig. $\left.3 E^{\prime}\right)$. Collectively, these data suggest that a specific proximodistal reorganization of coordinated hippocampal-entorhinal activity takes place in TLE, potentially reflecting upstream changes at MEC and LEC deep and superficial layers (Kumar and Buckmaster, 2006; Tolner et al., 2007).

\section{Proximodistal alterations of temporoammonic and medial perforant pathways in TLE rats}

The entorhinal cortex is specifically affected in TLE and this has been previously related with hippocampal sclerosis, the major histopathological hallmark of this disease (Du et al., 1995; Schwarcz and Witter, 2002). To examine whether structural changes of the sclerotic hippocampus could be related with the proximodistal reorganization of theta coordination, we quantified the thickness of the temporoammonic and perforant pathways in sections adjacent to the probe track using netrinG1 and G2 immunostaining in postmortem tissue from recorded rats $(n=10$ control, $n=9$ epileptic; Fig. 4A).

mal coordinates could account for these effects. Importantly, a proximodistal effect was dominant in our database, since classification of data in the anteroposterior axis showed no statistical effect $\left(F_{(1,88)}=0.15, p=0.6915\right.$; anterior implanting coordinates: -3 to $-4.9 \mathrm{~mm}$ from bregma; posterior: -5 to $-6 \mathrm{~mm}$ ).

For CSD signals, statistical analysis suggested a complex effect for the interaction between groups and recording locations $\left(F_{(1,45)}=11.6, p=0.0014\right.$; three-way ANOVA). Tukey's post hoc comparisons showed that this was caused by opposing trends of between-group differences of theta coherence in rats recorded at distal and proximal coordinates; i.e., CSD theta coherence was reduced in TLE rats recorded at proximal coordinates and increased in TLE rats recorded at distal coordinates (Fig. 3C'; one-tailed Welch's tests). These trends can be better appreciated for all layer interactions in the coherence matrices for distal (Fig. 3D) and proximal implanting locations (Fig. 3D'). Note that despite opposing trends in CSD signals, LFP coherence was decreased in TLE both at distal and proximal locations.

To gain additional insights, we compared proximodistal differences of theta coherence between CSD signals within groups. In control rats, a two-way $\operatorname{ANOVA}\left(F_{(1,53)}=4.9, p=0.0299\right)$ and Welch's tests confirmed that the strongest interacting cluster in the CSD coherence matrix shifted from within the DG (MLm, MLi, and GC) at distal to between SLM and ML sublayers at proximal sites (Fig. 3E). This reflects stronger coordination between the temporoammonic and perforant pathways that originate within the medial entorhinal cortex versus those originating from different mediolateral regions (Witter et al., 2000; Naber et al., 2001; Fig. 3A), and is consistent with stronger theta modulation of proximal CA1 cells by MEC activity in normal rats (Henriksen et al., 2010). In contrast, CSD signals from TLE rats exhibited a different pattern, with the strongest interacting cluster between SLM and ML sublayers occurring at the distal hippocampus and decreased within-DG interactions more localized
Consistent with hippocampal atrophy, CA1 thickness was reduced around the implanting location in epileptic rats both at the proximal ( $t$ Student, $p=0.0247$ ) and distal ends ( $p=0.0193$; Fig. $4 B ; F_{(1,36)}=9.4, p=0.0041$; two-way ANOVA, group effect). Interestingly, the thickness of the netrinG1-positive SLM band was significantly smaller in TLE rats at the proximal $(p=0.0069$; Fig. $4 A^{\prime}, B$ ) but not at the distal location (Fig. $4 A^{\prime \prime}, B ; F_{(1.36)}=3.6$, $p=0.0645$ for groups; $F_{(1,36)}=17.9, p<0.0001$ for location). This suggests that despite the widespread CA1 atrophy of the sclerotic hippocampus, specific reduction of the temporoammonic pathway is confined to the proximal end. This atrophy of the proximal temporoammonic pathway provides an anatomical substrate for reduced theta coordination recorded in TLE rats at proximal coordinates (Fig. $3 D^{\prime}$ ).

In contrast, group differences were found in the thickness of the netrinG1-positive MLo band $\left(F_{(1,30)}=13.3, p=0.0009\right)$ and the netrinG2-positive MLm band $\left(F_{(1,30)}=8.3, p=0.0072\right.$; Fig. $4 C)$ that were significantly increased in TLE rats both at distal (MLo, $p=0.0137$; MLm, $p=0.0281$; Fig. $4 A^{\prime}$ ) and proximal locations (MLo, $p=0.0052 ; \mathrm{MLm}, p=0.0134$; Fig. $4 A^{\prime \prime}$ ). Such an expansion of MLo and MLm terminals could provide a mechanism supporting increased theta coherence between distal entorhinal inputs in TLE (Fig. 3D). No differences were found for MLi at any location (Fig. 4C).

To better understand the causes underlying changes of thickness affecting the temporoammonic and perforant pathways, we examined neuronal loss at three different dorsoventral levels of the medial and the lateral entorhinal cortices (see Materials and Methods) using horizontal sections in a different cohort of rats ( $n=3$ control, $n=4$ epileptic; Fig. $4 D$ ). A two-way ANOVA for each level showed significant effect for the interaction between group and layers $\left(\mathrm{A}: F_{(3,20)}=17.9, p<0.0001 ; \mathrm{B}: F_{(3,20)}=6.5\right.$, $p=0.003)$, except for the ventral level where a layer effect dominated $\left(F_{(4,25)}=4.8, p=0.0053\right)$. Statistical differences of cell 


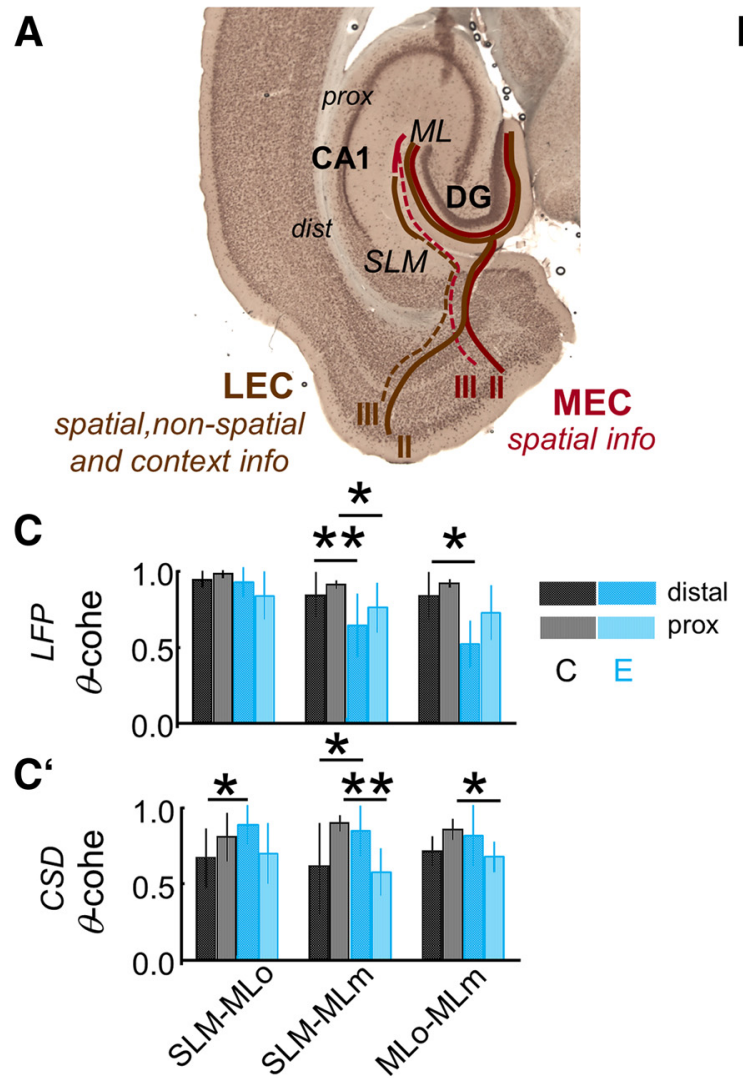

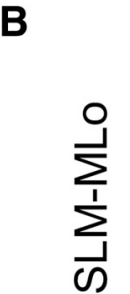
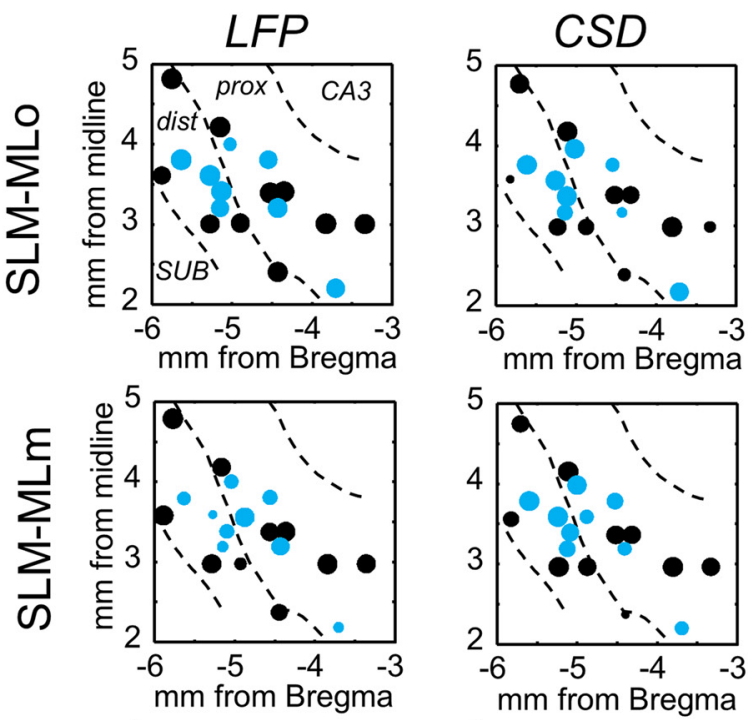

control

epileptic

$\theta$-cohe

1.00

$0.86 \bullet$

$0.72 \bullet$

$0.58 \bullet$

$0.44 \bullet$

0.30 •

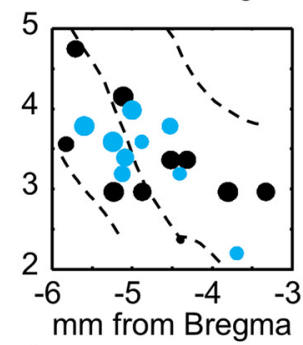

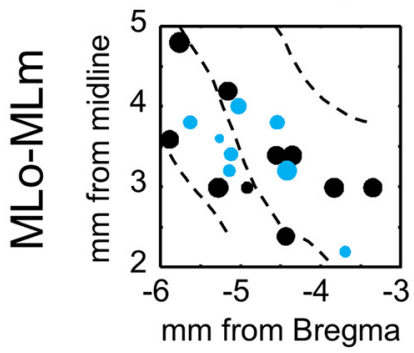

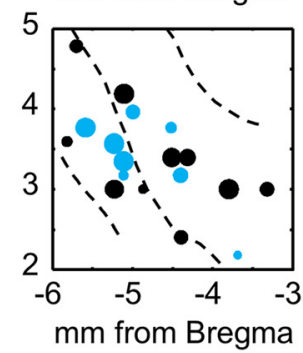

D، proximal layer-based $\theta$ cohe

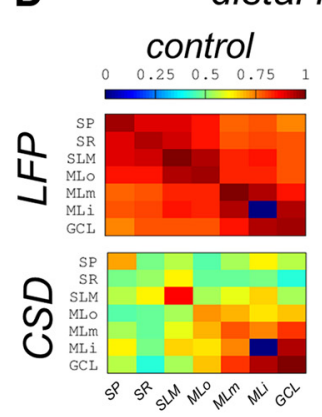

distal layer-based $\theta$ cohe

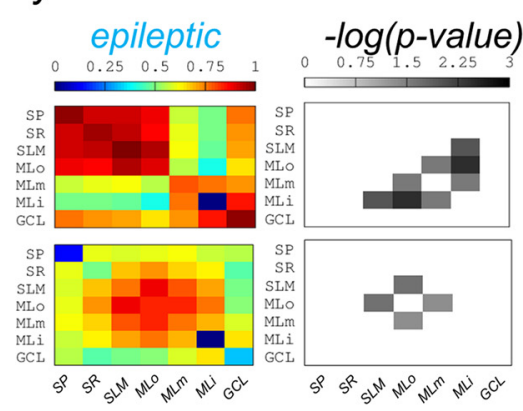

E

within-group (control)
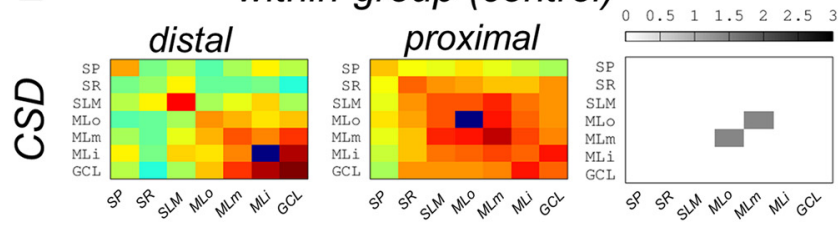
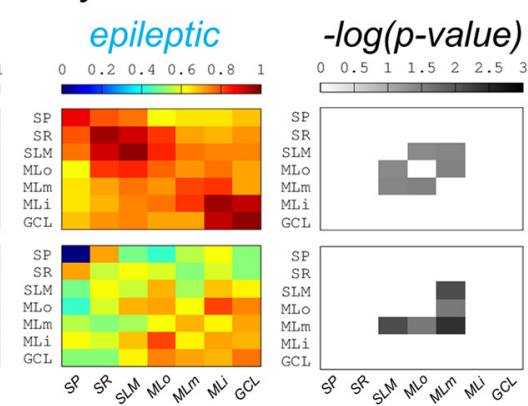

$E^{‘}$

within-group (epileptic)
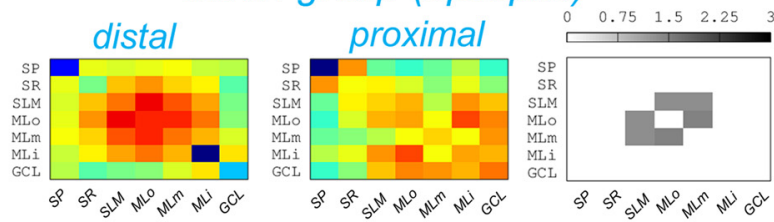

Figure 3. Proximodistal distribution of theta coherence in normal and epileptic rats. $\boldsymbol{A}$, Schematic representation of the entorhinal input pathways converging into the dorsal hippocampus. The temporoammonic pathway originates in layer III of the entorhinal cortex to target the SLM of CA1 region. Layer III neurons from the LEC project to distal CA1, i.e., close to the subiculum. Layer III neurons from the MEC project to the proximal CA1, i.e., close to CA3. The perforant pathway originates in layer II with LEC cells projecting to the MLo and MEC cells projecting to the MLm of the DG. LEC and MEC presumably process different aspects of information. B, Proximodistal distribution of theta coherence among SLM-MLo, SLM-MLm, and MLO-MLm for both LFP (left column) and CSD signals (right column). Individual data obtained from rats implanted at different mediolateral and anteroposterior locations are represented by dots scaled according to coherence (cohe) values (scale at right). Data from $n=10$ control (black), $n=9$ epileptic rats (blue). The approximate limits between proximal and distal CA1 are marked by discontinuous lines. One epileptic rat recorded at proximal coordinates had a defective site at MLO and could not be included in the SLM-MLo and MLm-MLO analysis. SUB, subiculum. C, Mean LFP coherence values per group at distal ( $n=5$ control, $n=4$ epileptic) and proximal coordinates ( $n=5$ control, $n=5$ epileptic). Data are represented as mean $\pm 95 \%$ confidence interval. Asterisks indicate significant differences between groups (one-tailed Welch's test); ${ }^{*} p<0.05,{ }^{* *} p<0.005$. $C^{\prime}$, Same for $(S D$ coherence values. $D$, Mean group layer-based coherence matrices for LFP and CSD signals recorded at distal locations together with the statistical contrast matrix (Welch's tests) for comparisons among SLM, MLo, MLm, and MLi layers as in matrices shown in Fig. 2. The level for Bonferroni correction is at $2.25=-\log 10(0.05 / 9)$. $\boldsymbol{D}^{\prime}$, Same as in $\boldsymbol{D}$ for rats recorded at proximal coordinates. $\boldsymbol{E}$, Within-group comparisons (control) of distal ( $n=5$ rats) versus proximal ( $n=5 \mathrm{rats})$ CSD coherence values. The contrast matrix shows only significant values (Welch's test). The level for Bonferroni correction is at $2.25=-\log 10(0.05 / 9)$. $\boldsymbol{E}^{\prime}$, Same as in $\boldsymbol{E}$ for proximal ( $n=5$ rats) and distal ( $n=4$ rats) comparisons within the epileptic group. $\mathrm{GCL}$, granule cell layer. 
A
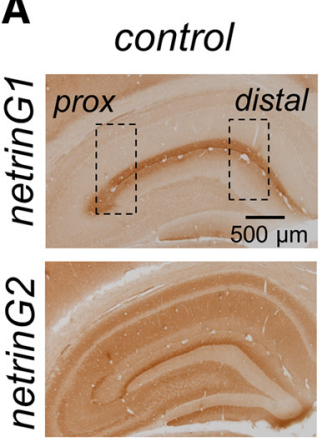

epileptic
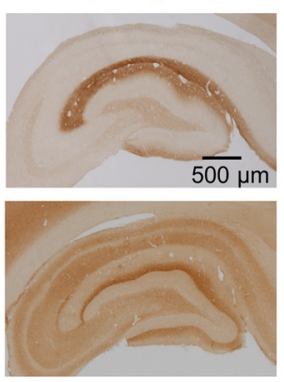

A‘ proximal
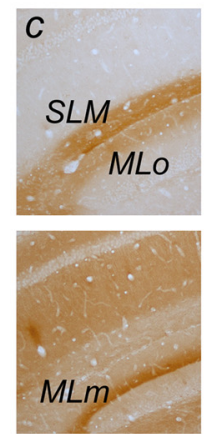
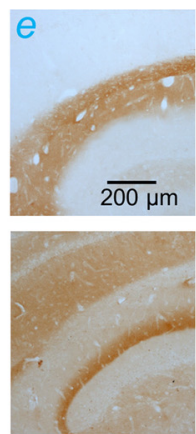

A“" distal
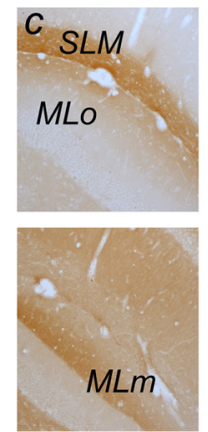
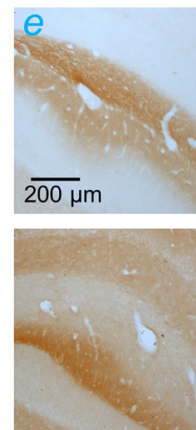

B

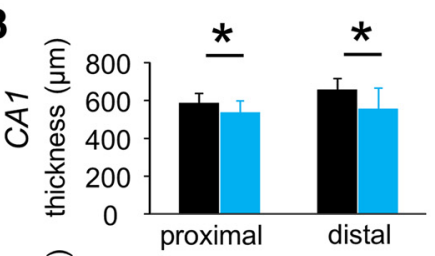

E

A-dorsal
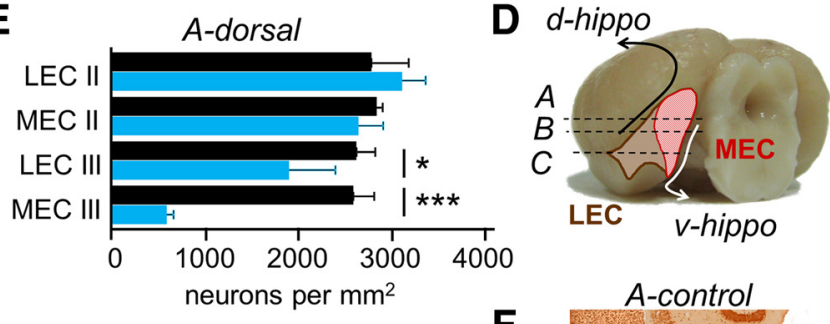

E'

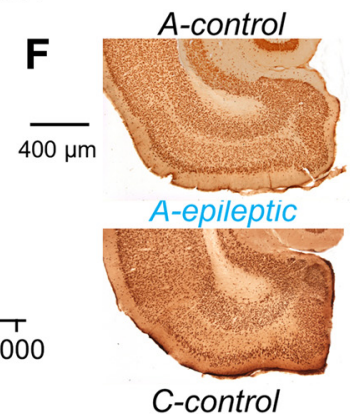

C

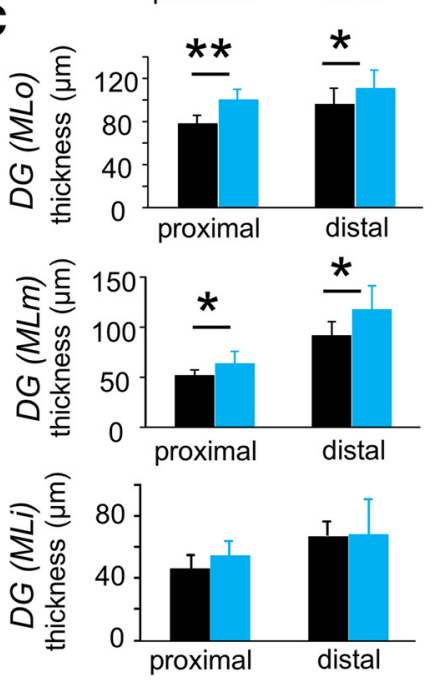

$E^{\prime \prime}$

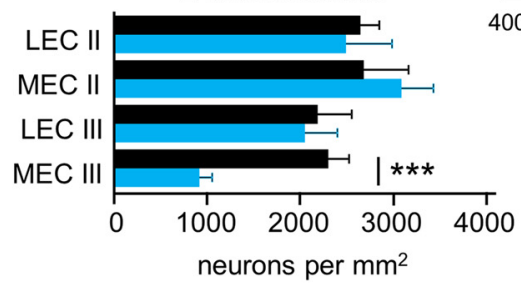

LEC II-fan
LEC II-pyr
MEC II
LEC III
MEC III

Figure 4. Structural alterations of the temporoammonic and perforant pathways in TLE. A, Immunostaining against netrinG1 and G2 was used to quantify changes of specific lamina in TLE. The thickness of different sublayers was measured at proximal and distal locations (squares) in sections adjacent to the recording probe. Images taken at $3.2 \times$ magnification. Images arranged vertically share scale bar. $\boldsymbol{A}^{\prime}$, For quantification purposes, images were taken at higher magnification (10X) at the proximal locations. C, control; e, epileptic. $\boldsymbol{A}^{\prime \prime}$, Higher magnification images taken at distal locations. $\boldsymbol{B}$, Proximal and distal group differences of CA1 and netrinG1-positive SLM thickness (mean \pm SD). Data from $n=10$ control (black) and $n=9$ epileptic rats (blue) as estimated from images at $10 \times$ magnification. ${ }^{*} p<0.05,{ }^{* *} p<0.01$. C, Proximal and distal group differences of the thickness of molecular strata as measured from netrinG1 (MLO) and G2 (MLm) immunostaining. MLi was measured from the ventral limit of netrinG2 band to the granule cell layer. Same dataset as in $\boldsymbol{B}$. D, Schematic representation of horizontal sections used to evaluate neuronal loss at LEC and MEC at different dorsoventral levels ( $A-C$; see Materials and Methods). $\boldsymbol{E}$, Quantification of neuronal density from different layers of the entorhinal cortex at dorsal levels. Data (mean \pm SD) from $n=3$ control (black), $n=4$ epileptic rats (blue). ${ }^{*} p<0.05,{ }^{* *} p<0.01$, and ${ }^{* * *} p<0.001$ for Bonferroni corrected $t$ tests. $\boldsymbol{E}^{\prime}$, Same as in $\boldsymbol{E}$ for intermediate horizontal levels. $\boldsymbol{E}^{\prime \prime}$, At ventral levels we differentiated between layer II fan cells and pyramidal cells. Same dataset as in $\boldsymbol{E}$ and $\boldsymbol{E}^{\prime}$. $\boldsymbol{F}$, Representative dorsal sections from a control and an epileptic rat. $\boldsymbol{G}$, Representative ventral sections from a control and epileptic rat.

density were concentrated at MEC layer III and were higher at dorsal (Fig. 4E,F) and intermediate levels (Fig. $4 E^{\prime}$ ) than at ventral levels of the entorhinal cortex (Fig. $4 E^{\prime \prime}, G$; Student's $t$ tests in all cases). Mild neuronal loss was also apparent at LEC layer III, but only at the dorsal level (Fig. $4 E, F$ ). Since MEC layer III cells give rise to the temporoammonic pathway terminating at the proximal end of CA1, these data are consistent with specific atrophy of netrinG1-positive band at proximal SLM (Fig. 4B) and give support to the idea that reduced theta coherence at the prox- imal hippocampus reflects specific impairment of the medial temporoammonic pathway.

In contrast, no cell loss was detected at MEC and LEC entorhinal layer II cells (Fig. $4 E, E^{\prime}$ ). At the ventral level (Fig. 4E'), LEC layer II cells can be classified as fan cells and pyramidal cells (Tahvildari and Alonso, 2005) and we counted them separately with no differences between groups. Importantly, enlargement of netrinG1- and netrinG2-positive bands at MLo and MLm cannot be explained by changes in the number of projecting cells at MEC 

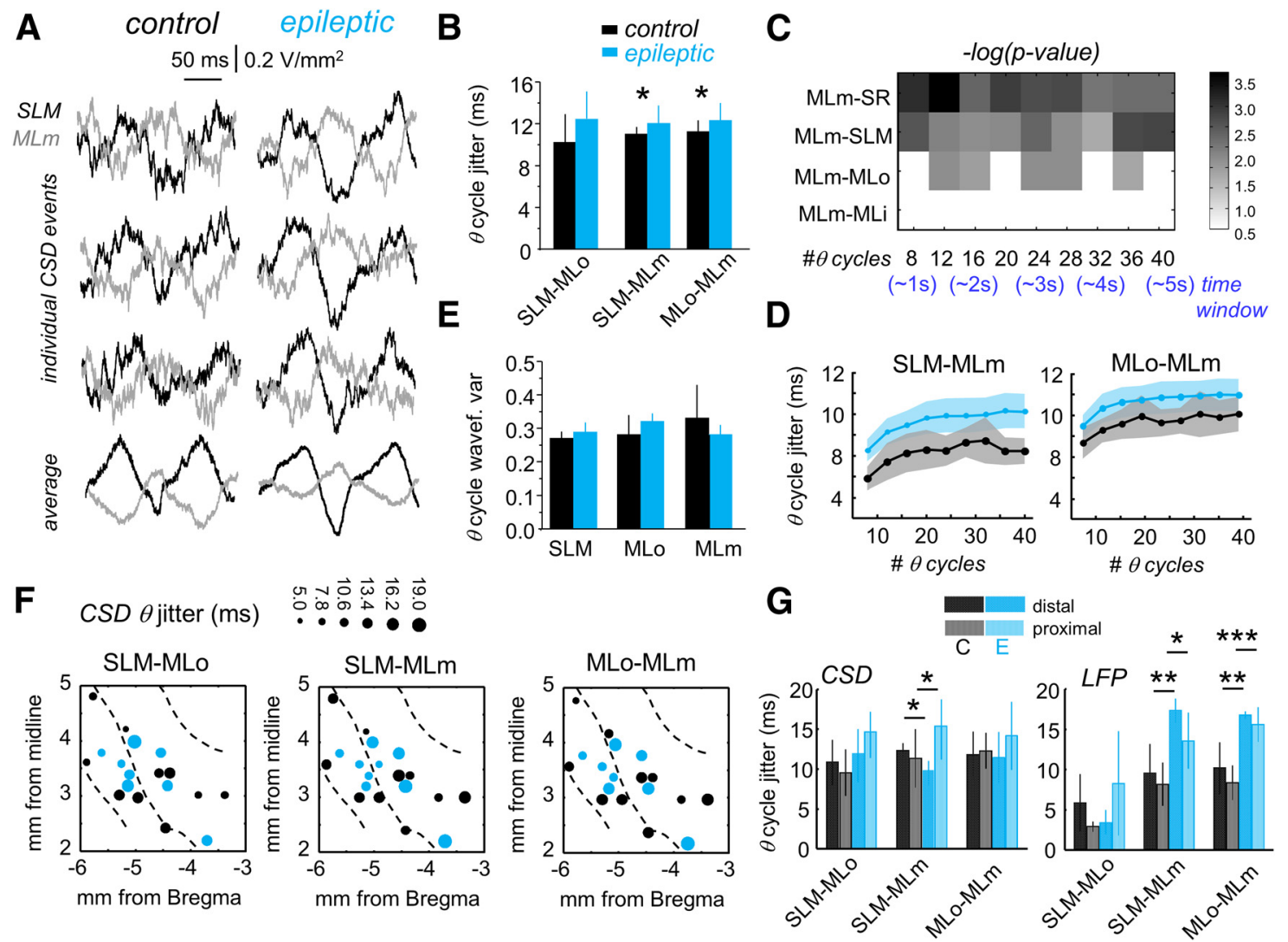

Figure 5. Temporal precision between entorhinal current sinks during exploratory theta. $A$, Theta current sinks at SLM and MLm are systematically out of phase in control rats (left), but exhibited large fluctuations in epileptic animals (right). Three individual events from a representative control and epileptic rat are shown. Average traces were estimated from all events in the given session. $B$, Timing variability (jitter; mean $\pm 95 \%$ confidence interval) of intersink interval estimated in windows of 2 s is larger in epileptic (blue) than control rats (black). ${ }^{*} p<0.016$, Bonferroni corrected. C, $P$ values for between-group statistical differences of intersink jitter estimated over a different number of cycles (time windows). Data show significant $p$ values (expressed as - log 10 ) resulting from a Welch's test. The level for Bonferroni correction is at $2.85=-\log 10(0.05 / 36)$. D, Group data (epileptic, blue; control, black) of CSD theta cycle jitter between SLM-MLm (left) and MLo-MLm (right). Data are given as mean $\pm 95 \%$ confidence interval. $\boldsymbol{E}$, Group data (mean $\pm 95 \%$ confidence interval) on variability of CSD waveform did not reach significance. $\boldsymbol{F}$, Proximodistal distribution of intersink jitter between different layers (SLM-MLm, SLM-MLm, and MLo-MLm) for control (black) and epileptic (blue) rats. Dot size reflects CSD jitter values (in milliseconds) according to the scale shown at top. One epileptic rat recorded at proximal coordinates had a defective site at MLo and could not be included in the SLM-MLo and MLm-MLo analysis. G, Mean jitter values per group for CSD (left) and LFP (right) signals recorded at distal ( $n=5$ control, $n=4$ epileptic) and proximal locations ( $n=5$ control, $n=5$ epileptic) from animals shown in $F$. ${ }^{*} p<0.05$, ${ }^{* *} p<0.01$, and ${ }^{* * *} p<0.005$, Bonferroni corrected.

layer II. Instead, it could be reflecting some kind of reorganization of axonal terminals. This reorganization of the medial entorhinal pathway could explain the opposing trend of group differences of CSD theta coherence at proximal and distal locations (Fig. $3 E, E^{\prime}$ ).

Our data support the idea that coordinated theta activity is specifically impaired in the TLE hippocampal-entorhinal system, caused by cell loss in layer III of the medial entorhinal cortex and expansion of the perforant pathway originating from layer II cells. Proximodistal changes of the afferent entorhinal pathways act to reorganize the coordination between temporoammonic and perforant synaptic inputs in the dorsal hippocampus of TLE rats. Consequently, TLE-associated reduction of coherent theta activity is more pronounced at the proximal CA1 region where the medial temporoammonic pathway is affected, while increases of theta coordination between CSD signals tend to occur at distal CA1 in association with reorganization of the medial perforant pathway. These opposing trends of synaptic inputs negatively impact the proximodistal profile of LFP oscillations in TLE rats that exhibit a widespread reduction of theta coordination. This reflects the mixing influence of layer-specific generators of theta activity together with volume-conducted effects over LFP signals.
Temporal variability between entorhinal inputs underlies theta coherence disruption in TLE

While cell loss occurs in the MEC layer III of TLE rats, surviving neurons contribute a netrinG1-positive band at SLM, indicating that some synaptic inputs still reach the dorsal hippocampus. In addition, expansion of netrinG2-positive MEC layer II terminals could be affecting theta coordination at distal locations. Since coherence of CSD theta activity between sites reflects phase variations between local synaptic current generators (i.e., CSD sinks), we explored the underlying mechanisms by examining the temporal dynamics of synaptic sinks recorded at SLM, MLo, and MLm (Brankack et al., 1993).

CSD sinks between SLM and MLm both in control and TLE rats were systematically out of phase (Fig. $5 \mathrm{~A}$ ). However, we noted large fluctuations of both the timing and waveform of theta cycles in epileptic rats (Fig. 5A, right). On average, the phase of theta sinks at different layers against SLM was similar between groups $\left(F_{(1,14.01)}=0.3993\right)$. Differences were found in the variability of intersink interval, i.e., theta cycle jitter $\left(F_{(1,36)}=6.9, p=\right.$ 0.0124, two-way ANOVA), reflecting longer jitter in SLM-MLm and MLo-MLm in TLE rats when examined in windows of $2 \mathrm{~s}$ (Fig. $5 B$ ). We wondered whether theta jittering could be compen- 
sated over consecutive cycles so that differences vanish over time. We found that temporal variability accumulated and group differences were robust over different temporal scales (Fig. 5C,D; Welch's tests).

We also checked whether the waveform of CSD theta cycles was different between groups, since covariation of theta waveform between layers might impact theta coherence. We found nonsignificant differences between groups (Fig. $5 E ; F_{(1,41)}=$ $2.7718, p=0.1036$ ). Thus, while covariations of theta waveform could contribute, it seems that phase variations between entorhinal synaptic sinks of the temporoammonic and the medial perforant pathways have stronger impact on the coordination between these inputs over consecutive theta cycles.

To gain a wider view we plotted the values of CSD cycle jitter in their corresponding anteroposterior and mediolateral coordinates for SLM-MLo, SLM-MLm, and MLo-MLm (Fig. 5F). A three-way ANOVA showed effects for group $\left(F_{(1,44)}=6.9, p=\right.$ $0.0116)$ and location $\left.\left(F_{(1,44)}\right)=8.3, p=0.0061\right)$ but not for pairs of layers. A closer examination confirmed that this was due to opposite proximodistal effects concentrated at SLM-MLm (Fig. $5 G$, left), consistent with coherence data reported above. This suggests a striking inverse correspondence between CSD jitter and coherence values: the larger the jitter the lower the coherence and vice versa ( $r=0.66, p=0.0021$; linear regression). Group differences were evident for LFP signals, as tested either with a three-way ANOVA $\left(F_{(1,44)}=23.3, p<0.0001\right)$ or with two-way ANOVA for SLM-MLm and MLo-MLm (Fig. 5G, right), indicating that for LFP signals timing variability between theta cycles was typically larger in TLE regardless of location. This was consistent with a widespread reduction of theta coherence between LFP signals recorded in TLE rats, and might reflect the dominant volume-conduction effect of CSD theta coherence reduction at proximal coordinates. Other TLE-associated alterations affecting the coordination between glutamatergic and GABAergic hippocampal microcircuits during theta activity (Csicsvari et al., 1999; Peng et al., 2013) could be also related with a differential effect at proximal and distal locations.

\section{Correcting timing variability computationally repairs hippocampal theta coherence in TLE rats}

Data above support the idea that timing variability between entorhinal synaptic inputs over several theta cycles contributes to theta coherence disruption in TLE. If so, manipulations that correct temporal variability of theta cycles should affect repairing theta coherence. Since variability of the theta cycle waveform could also play a role, we considered the possibility of a waveform effect on coherence. Actually, variability of theta cycle waveform and jitter were correlated for all three pairs: SLM-MLo, SLMMLm, and MLo-MLm (mean Pearson $r$ value, $0.55 \pm 0.08$; binomial test on results of permutation tests on regression $R^{2}$ values, with $n=6$ regressions and $p=0.05 ; p<0.0001$ ).

We further tested this idea computationally by designing a correction procedure aimed to reduce variability between CSD cycles in TLE rats using windows of $2 \mathrm{~s}$ (see Materials and Methods). To this purpose we first detected individual CSD theta cycles $(>2 \mathrm{SD})$ in a reference layer and the corresponding cycles in the layer to be corrected. Two types of corrections were implemented: a waveform correction (Fig. $6 A$ ) and a jitter correction (Fig. 6B). To correct waveform variability, each detected cycle in the corrected layer was substituted by the mean waveform cycle for that layer calculated from the entire recording session, but preserving the intersink interval. Jitter variability was corrected by shifting each cycle to the mean intercycle interval between the reference and the corrected layer. Correction was implemented on one layer at a time (SLM, MLo, or MLm) using windows of $2 \mathrm{~s}$. Resulting CSD signals were used to estimate the corrected LFP according to the field equation (see Materials and Methods; Pettersen et al., 2006) in each window and results averaged across windows. This way we asked whether acting in a particular layer had a major effect in rescuing coherence values in LFP signals of the entire hippocampus. Correction outcome was evaluated by statistically testing theta coherence of the corrected LFP signals $\left(\mathrm{LFP}^{\prime}\right)$ versus that of LFP signals obtained from the original CSD ( $z$-score). We chose three TLE rats with sufficient number of cycles per window detected in each of the three layers.

As expected, reducing variability of the waveform (Fig. 6C) or of the jitter (Fig. $6 D$ ) of CSD theta cycles significantly increased theta coherence between LFP signals (SLM-MLo, SLM-MLm, and MLo-MLm; Fig. $\left.6 C-C^{\prime \prime}, D-D^{\prime \prime}\right)$. Remarkably, we found stronger effect of jitter correction than waveform correction, as tested with a three-way ANOVA with the type of correction, pairs of layers, and windows as factors $\left(F_{(1124)}=12.3287 p<0.0001\right)$, confirming that consistent timing between CSD theta sinks has a major effect in coordinated theta activity. Our results also revealed a spatial effect for both waveform and jitter correction. More reliable increases of LFP theta coherence were obtained when variability was corrected in sublayer MLm using SLM or MLo as a reference (Fig. 6E,F). This indicates that timing variability of synaptic sinks between MLm and SLM and between MLm and MLo dominates the appearance of theta cycles recorded in the local field potential.

To better understand how CSD jittering of theta cycles impacts LFP coherence, we performed a parametric study by imposing a specific jitter to the intersink interval between layers. In each window, jittering was corrected in different cycles (7-8 cycles) both in the backward and forward direction to preserve main phase difference between layers. As expected, increasing the jitter resulted in decreased LFP theta coherence $(r=-0.87, p=$ $0.0026)$. Therefore, increases of CSD theta coherence recorded at distal locations in TLE rats (Fig. 3D) cannot explain widespread reduction of LFP theta coherence (Figs. $2 A, 3 D, D^{\prime}$ ), giving further support to the idea that complex volume conduction and microcircuit interactions are in place.

Overall, our computational experiments predict that restoring temporal variability between the lateral and medial perforant inputs at the proximal hippocampus in TLE rats should affect the coordination of theta oscillations. However, given the complex proximodistal reorganization occurring in the entorhinal inputs, we reasoned that CSD changes should be fully corrected at both the distal and proximal locations to better account for spatial effects at the LFP.

\section{Correcting timing variability pharmacologically repairs hippocampal theta coherence in TLE rats}

To test these ideas we looked for pharmacological agents acting globally in the hippocampus and entorhinal cortex to modulate the activity of the entorhinal inputs presynaptically. We chose to act over group III metabotropic receptor mGluRs (mGluR4, 7, and 8) given their specific expression in the temporoammonic and perforant synapses terminating over hippocampal principal cells and interneurons (Shigemoto et al., 1997; Ferraguti et al., 2005), allowing for a concerted modulation of theta dipoles (Montgomery et al., 2009). We selected their specific agonist (L-AP4) and antagonist (CPPG; Mercier et al., 2013) to check for their ability to modulate entorhinal theta inputs. In pilot experiments we found no clear effect of L-AP4 (5-10 mg/kg; $n=3$ sessions $/ n=1$ rat $)$ in 
A

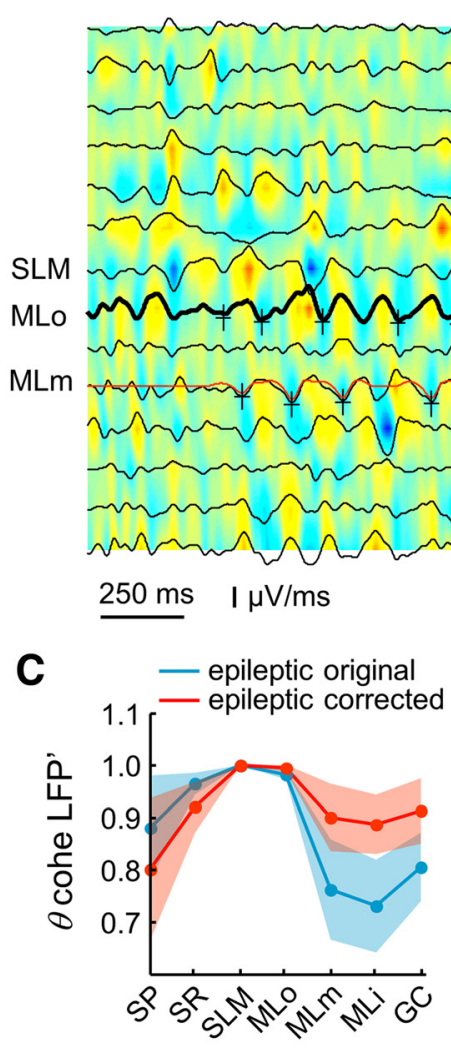

E

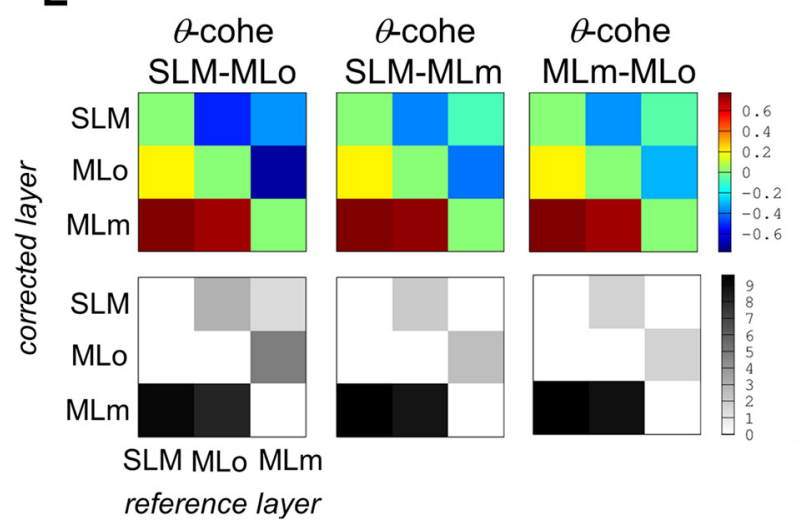

C، SLM-MLm

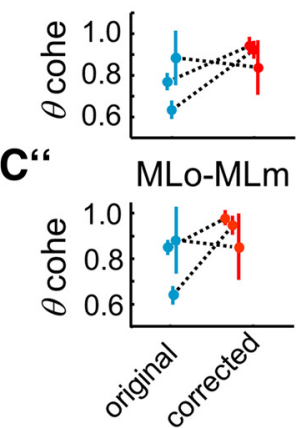

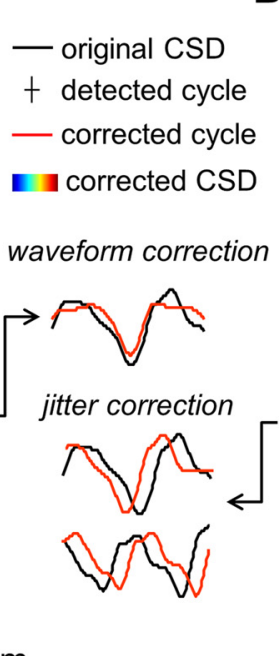

B

B jitter correction

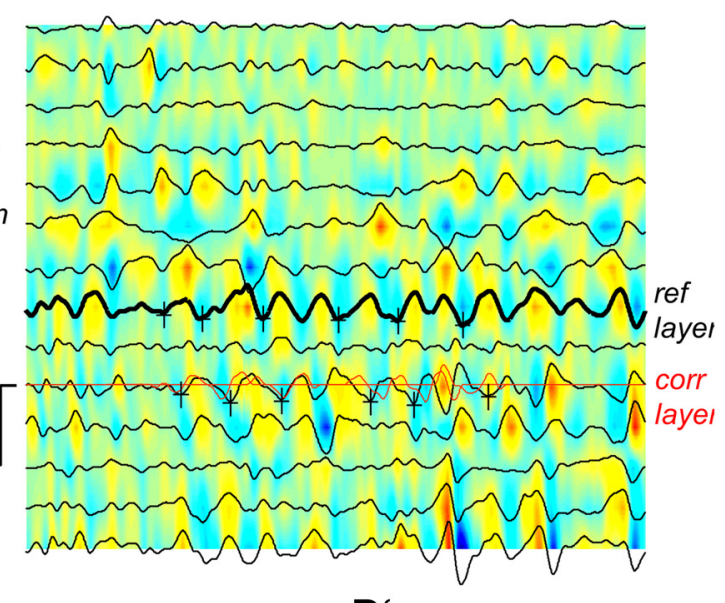

D

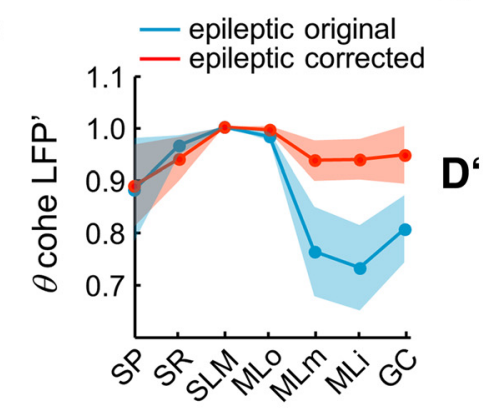

$\mathbf{F}$

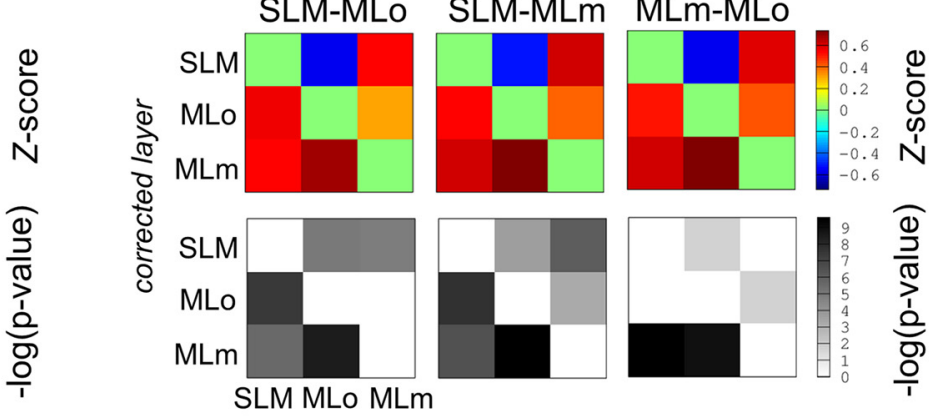

Figure 6. Computational correction of intersink variability between layers. $\boldsymbol{A}$, We implemented a procedure to evaluate the impact of correcting intersink variability between two layers, i.e., a reference layer (thick black trace) and the corrected layer (red trace), in LFP theta coherence. To correct waveform variability, each CSD-detected cycle in the corrected layer was substituted by the mean CSD waveform for the entire session while preserving variability of intersink interval and amplitude. LFP obtained from uncorrected (black traces) and corrected CSD signals (color map) were contrasted using $z$-scores and paired $t$ tests. $B$, Jitter variability was corrected by shifting each detected CSD cycle to the mean intercycle interval between the reference and the corrected layers, thus neglecting temporal variability. $\boldsymbol{C}$, Effect of correcting CSD waveform variability in LFP recordings from $n=3$ epileptic rats. Data are represented as mean $\pm 95 \%$ confidence interval. $\boldsymbol{C}^{\prime}$, Individual changes of SLM-MLm theta coherence (cohe) before and after waveform corrections. Individual data are shown as mean (dots) and $95 \%$ confidence interval (bars) as calculated from several windows (2 s) in a given rat per session. $\boldsymbol{C}^{\prime \prime}$, Same as in $\boldsymbol{C}^{\prime}$ for MLo-MLm. $\boldsymbol{D}$, Effect of correcting CSD jitter variability in the same $n=3$ epileptic rats corrected in $\boldsymbol{C}$ for the waveform (mean $\pm 95 \%$ confidence interval). $\boldsymbol{D}^{\prime}$, Individual changes of SLM-MLm theta coherence before and after jitter correction. $\boldsymbol{D}^{\prime \prime}$, Same as in $\boldsymbol{D}^{\prime}$ for MLo-MLm. $\boldsymbol{E}$, Statistical changes due to waveform correction obtained in the rat shown in $\boldsymbol{A}$ ( $z$-score and $-\log 10$ of $p$ value) as a function of the corrected and the reference layer. Nine different comparisons were performed using data from several windows $(2 \mathrm{~s})$ for each given animal. Only significant values (Bonferroni corrected) are represented. Note best results obtained when MLm is corrected using either SLM or MLo as reference layer. $\boldsymbol{F}$, Same as in $\boldsymbol{E}$ for jitter correction as shown in $\boldsymbol{B}$.

SLM-ML interactions, consistent with downregulation of mGluR8 and its loss of function in TLE (Dietrich et al., 1999; Klapstein et al., 1999). Therefore we focused on testing the mGluR-III antagonist CPPG with promising preliminary data.

Single intraperitoneal injections of CPPG (2 mg/kg) successfully repaired LFP theta coherence in the dorsal hippocampus of
TLE rats ( $n=6$ rats), as evaluated $1 \mathrm{~h}$ after injection (Fig. $7 A$, top matrices).This was confirmed by a two-way ANOVA effect for group (predrug vs CPPG, $F_{(1,62)}=7.8, p=0.0068$ ) and group/ layer interactions $\left(F_{(6,62)}=3.3, p=0.0069\right)$. CPPG effect on theta coherence between LFP signals concentrated at SLM-MLm layers (Fig. $7 B$ ) in all rats tested (Fig. $7 B^{\prime}$; paired $t$ test), reinforcing 
A

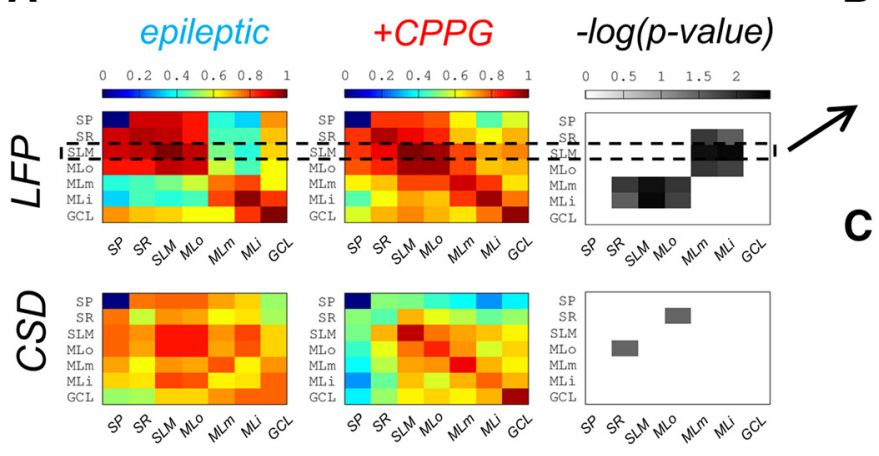

D

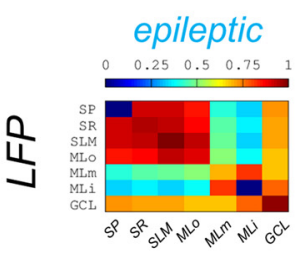

distal layer-based $\theta$ cohe

ڤ
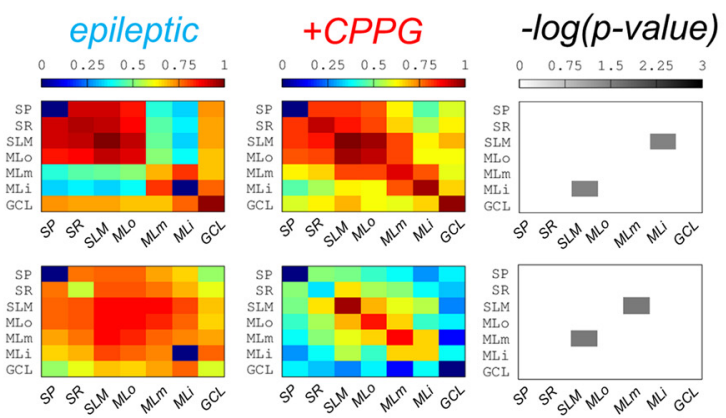

E

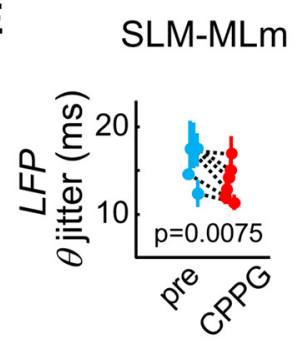

E'

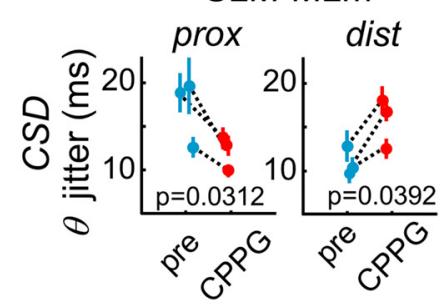

D'

$\mathbf{F}$
B

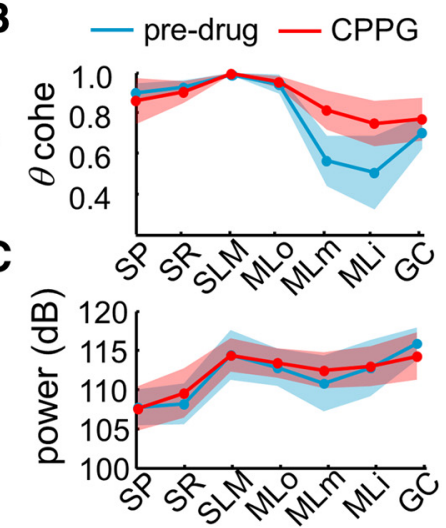

B'

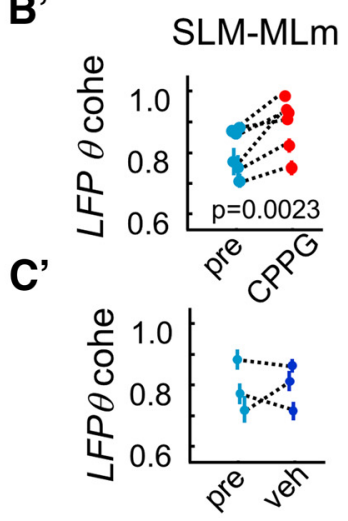

proximal layer-based $\theta$ cohe

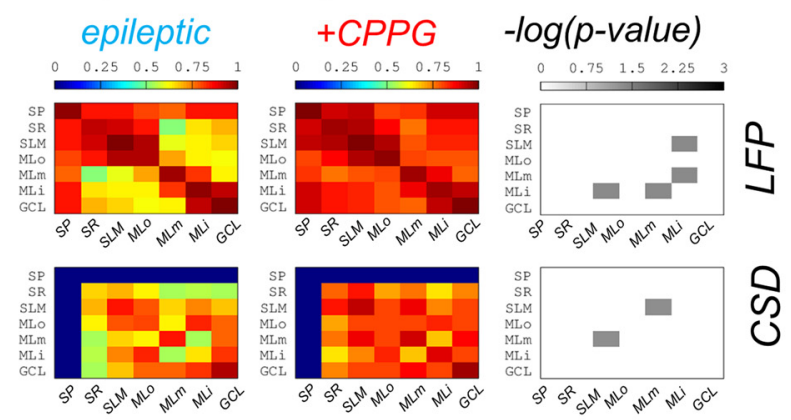

$\theta$ input coordination (CSDs)

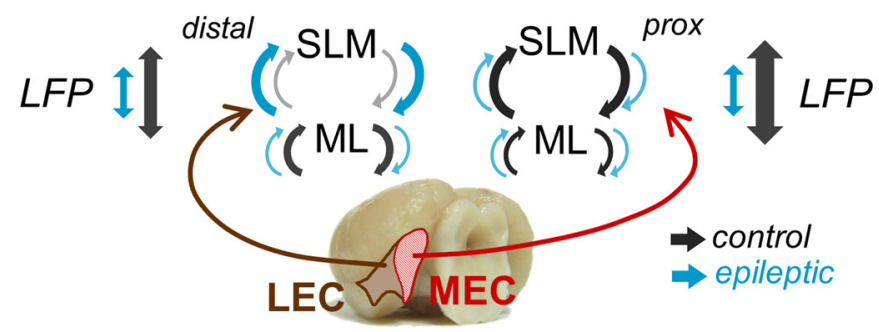

Figure 7. Pharmacological rescue of theta coherence. $A$, Mean layer-based coherence matrices for LFP (top) and CSD signals (bottom) $1 \mathrm{~h}$ before and after intraperitoneal injection of the type III mGluR antagonist CPPG ( $2 \mathrm{mg} / \mathrm{kg})$ in $n=6 \mathrm{TLE}$ rats. The contrast matrix (Welch's test) showing significant $p$ values as $-\log 10$ for all pairs of layers is shown at right. The level for Bonferroni correction is at $2.75=-\log 10(0.05 / 28)$. Note significant differences in LFPs, but poor statistical contrast for CSD signals. B, CPPG had strong effect in rescuing LFP theta coherence between SLM and ML layers in all epileptic rats. Group data before (blue) and after CPPG (red) are shown as mean $\pm 95 \%$ confidence interval. Note statistical differences concentrated at SLM-MLm. The arrow from $\boldsymbol{A}$ to $\boldsymbol{B}$ indicates data correspondence. $\boldsymbol{B}^{\prime}$, Individual data on LFP theta coherence between SLM and MLm before (blue) and after CPPG (red). $P$ values correspond to results from paired $t$ tests. Individual data are shown as mean (dot) and $95 \%$ confidence interval (bar) as estimated from several windows of 2 s from the whole recording session (300 s). C, CPPG injection had no effect on theta power along the CA1-DG axis. Data shown as mean $\pm 95 \%$ confidence interval. $\boldsymbol{C}^{\prime}$, No effect of vehicle (dark blue) on SLM-MLm LFP coherence was appreciated in $n=3$ rats tested. $\boldsymbol{D}$, Layer-based coherence matrices estimated from those epileptic rats shown in $A$ recorded at distal locations $(n=3)$ before and after CPPG. $\boldsymbol{D}^{\prime}$, Layer-based coherence matrices estimated from epileptic rats shown in $\boldsymbol{A}$ recorded at proximal locations before and after treatment with CPPG $(n=3)$. $E$, Jitter between theta cycles in LFP recordings at SLM and MLm before and after CPPG. $P$ value corresponds to results from paired $t$ tests. Note opposite trends compared with LFP coherence $\left(\boldsymbol{B}^{\prime}\right)$ indicating that CPPG restores theta coherence by reducing theta cycle jittering at the LFP. $\boldsymbol{E}^{\prime}$, CSD jitter between theta cycles in SLM-MLm before and after CPPG grouped according to proximal $(n=3)$ and distal locations $(n=3)$. $P$ value corresponds to results from paired $t$ tests. Note opposing trends at proximal and distal locations. $\boldsymbol{F}$, Schematic representation summarizing differences of entorhinal input coordination (CSDs) between SLM and ML and within ML layers at distal and proximal locations and the effect on LFP theta coherence (denoted by arrows of different thicknesses) in the dorsal hippocampus of normal (black) and epileptic rats (blue). GCL, granule cell layer.

the idea that modulation of entorhinal inputs has major impact on the coordination of hippocampal theta activity. We also noted a significant effect on the peak of theta frequency (paired $t$ test, $p=0.0073$ ), which slightly accelerated with CPPG injection (predrug $7.2 \pm 0.5 \mathrm{~Hz}$; CPPG 7.6 $\pm 0.6 \mathrm{~Hz})$. Remarkably, CPPG had no effect on the theta power (Fig. $7 C$ ). Vehicle injections did not affect theta coherence (Fig. $7 C^{\prime} ; n=3$ TLE rats), theta frequency, or theta power (data not shown). No differences of rat mean speed before and after drug injection accounted for the effect of CPPG (Student's $t$ test, $p=0.2521$ ).
In CSD signals, a two-way ANOVA failed to detect any significant effect (Fig. 7A, bottom matrices), suggesting large variability in all six TLE rats. When separated by implanting location, significant opposing effects of CPPG on SLM-MLm coordination between theta sinks were evident both at distal (Fig. $7 D ; n=$ 3 ; decreases) and proximal locations (Fig. $7 D^{\prime} ; n=3$; increases). Jittering of LFP theta cycles (Fig. 7E) but not waveform variability (data not shown) was significantly reduced by CPPG, consistent with our conclusions from computational experiments suggesting a major role of jitter versus waveform. Jittering between CSD 
theta sinks before and after CPPG was successfully corrected at proximal $(p=0.0312 ; n=3$ rats $)$ and distal locations $(p=$ $0.0039 ; n=3$ rats; Fig. $\left.7 E^{\prime}\right)$. Thus reducing group III mGluR activity in the epileptic hippocampus appears to correct opposing proximodistal trends of timing variability between entorhinal sinks, reinforcing the idea of complex neuronal processes being involved.

\section{Discussion}

Our data help to clarify how coordinated theta oscillations are implemented and degraded in the hippocampal-entorhinal system. We found that the precise timing between entorhinal theta sinks arriving at SLM, MLo, and MLm is disrupted in epileptic rats. TLE rats suffer from a strong proximodistal reorganization of input coordination due to shrinkage of the proximal temporoammonic pathway associated with loss of layer III cells of the medial entorhinal cortex and the laminar expansion of layer II terminals at the perforant pathway. These connectivity changes of entorhinal afferents ran parallel with changes in the coordination of synaptic sinks reaching the hippocampus at SLM, MLo, and MLm layers. Correcting intersink timing alteration over theta cycles has a major impact on repairing LFP theta coherence in TLE rats, as confirmed both computationally and pharmacologically with the selective group III mGluR antagonist CPPG.

Structural changes found at the hippocampal-entorhinal system of TLE rats specifically affect the medial and lateral temporoammonic and perforant pathways targeting proximal and distal SLM and ML layers of the dorsal hippocampus. According to our data, in normal rats entorhinal inputs arriving at SLM and ML during theta oscillations are better coordinated at proximal regions in the dorsal hippocampus while stronger intradentate interactions remain distally confined (Fig. $7 F$ ). These observations are consistent with proximodistal gradients (CA3 to subiculum) of spatial tuning of CA1 cells (Henriksen et al., 2010), with the topography of entorhinal afferents to the dorsal hippocampus (Tamamaki and Nojyo, 1995; Witter and Moser, 2006), and with stronger theta modulation of MEC neurons as compared with LEC (Deshmukh et al., 2010; Henriksen et al., 2010). Thus, together with differences of intrinsic excitability (Masukawa et al., 1982; Jarsky et al., 2008), collectively these data support the emerging concept that the operation of the normal hippocampal-entorhinal loop is exquisitely organized in the proximodistal axis (Bellistri et al., 2013; Hartzell et al., 2013; Nakamura et al., 2013).

In TLE rats, several changes occur in the hippocampal-entorhinal system in association with the underlying pathology (Schwarcz and Witter, 2002). Cell loss of MEC layer III cells is a common feature in epileptic humans and rodents, likely reflecting vulnerability to repeated seizures (Du et al., 1995). Using lamina-specific immunostaining against netrinG1 and G2 (Nishimura-Akiyoshi et al., 2007), we confirmed that the temporoammonic pathway was reduced at proximal CA1 in TLE. This is consistent with layer III cell loss in MEC but not in LEC and supports the idea that TLE mainly affects projecting glutamatergic cells (Drexel et al., 2012). Thus, loss of temporoammonic synapses at proximal regions acts to disconnect MEC and CA1 areas, possibly impeding the transfer of the entorhinal spatial metric in TLE rats (Lenck-Santini and Holmes, 2008). However, the medial perforant pathway generated by layer II MEC cells was enlarged in these animals while the density of layer III LEC cells giving rise to the distal temporoammonic pathway did not change. It is thus possible that spatial information from LEC is maintained by these pathways (Hales et al., 2014), together with alternative circuits (Brun et al., 2008; Kohara et al., 2014). Indeed, we discovered a profound proximodistal reorganization of entorhinal input coordination in TLE rats that shifted SLM-ML synaptic interactions from proximal to distal locations (Fig. 7F).

The proximodistal reorganization of entorhinal inputs in TLE was associated with a thicker netrinG2-positive band at MLm and MLo. Since the number of layer II cells was found to be preserved in LEC and MEC regions of TLE rats, this probably reflects the reorganization of layer II terminals into dendritic regions of granule cells. Possibly, loss of hilar cells with dendrites in the ML (Scharfman, 1991) and/or newly generated ectopic granule cells (Parent et al., 1997; Scharfman et al., 2003) accounts for such sprouting of terminals (Sloviter et al., 2012). At the entorhinal cortex, deep-to-superficial neuronal interactions are shaped by specific membrane and connectivity properties (Alonso and Llinás, 1989; Giocomo and Hasselmo, 2008) that form highly specialized and modular local circuits (Kloosterman et al., 2003; Quilichini et al., 2010; Burgalossi et al., 2011; Ray et al., 2014). Under TLE conditions, when neuronal loss affects MEC layer III, these circuits undergo functional reorganization resulting in higher excitability caused by modifications of intrinsic and synaptic properties (Kumar and Buckmaster, 2006; Tolner et al., 2007; Huang et al., 2009). Hence, abnormal circuits are established between cells in the superficial layers (Kobayashi et al., 2003; Kumar et al., 2007; Tolner et al., 2007) and the whole hippocampal-entorhinal system (Avoli et al., 2002; Ang et al., 2006). While these modifications have been typically associated with hyperexcitability and ictogenesis in the epileptic temporal lobe, they may also fundamentally affect circuit operation in seizurefree periods. Possibly, similar circuits are responsible for seizures and cognitive defects in these TLE rats (Inostroza et al., 2011, 2013), providing a neuronal basis for behavioral comorbidities of epilepsy. The stronger interaction between SLM-ML current sinks at distal coordinates in epileptic rats is thus likely reflecting these functional modifications and characterizes the complexity of changes affecting the hippocampal-entorhinal system in TLE (Fig. $7 F$ ).

How do proximodistal changes of entorhinal inputs to the dorsal hippocampus affect temporal lobe physiology? During exploratory theta activity, the concerted action of several theta dipoles interact in the dorsal hippocampus to efficiently coordinate hippocampal regions and layers (Montgomery et al., 2009; Tort et al., 2009; Benchenane et al., 2010; Penley et al., 2013). We found that when the timing between entorhinal sinks at the proximal and distal hippocampus was disrupted (TLE condition) the coherence of LFP theta oscillations was reduced, while repairing timing coordination in TLE (either computationally or pharmacologically with a type III mGluR agonist) had a beneficial effect on theta coherence, reinforcing the idea that entorhinal input coordination serves specific functional processes in the temporal lobe (Montgomery et al., 2009; Tort et al., 2009; Suh et al., 2011; Igarashi et al., 2014). Presumably, CPPG can exert its role by modulating glutamate release at the outer perforant pathway via presynaptic mGluR8 receptors (Dietrich et al., 1999); however, it may also act over type II mGluR at the temporoammonic and medial perforant pathways (Shigemoto et al., 1997). A direct action of CPPG over the perforant pathway would tend to facilitate glutamate release at the synapses over granule cells, probably compensating for a basal mGluR8 downregulation in TLE that leaves these receptors saturated (Kral et al., 2003). This interpretation is consistent with the poor effect of mGluR-III agonist L-AP4 in the epileptic hippocampus (Dietrich et al., 1999; Klapstein et al., 1999). Possibly, compensatory mechanisms aimed to 
counteract seizure-associated hyperexcitability interfere with an appropriate microcircuit operation in seizure-free periods. The differential effect of CPPG on correcting intersink timing at proximal and distal locations suggests that the mechanism of action is rather more complex and operates at the circuit level. A contrasting facilitatory effect of presynaptic mGluR-III over glutamate release has been described in layer V MEC (Evans et al., 2000), which coordinates activity at superficial layer cells. Other prominent targets of mGluR-III synapses are GABAergic cells that express muscarinic M2 receptors and fire strongly during theta (Ferraguti et al., 2005). Therefore, CPPG could also mediate presynaptic gain of function of a subset of GABAergic interneurons (Poncer et al., 1995; Cosgrove et al., 2011; Semyanov and Kullman 2000). Possibly, a concerted action of CPPG at glutamatergic and GABAergic terminals is related with their overall effect in repairing coordination of LFP theta oscillations in TLE rats. Indeed, aberrant GABAergic circuits controlled by mGluR activity in the epileptic hippocampus are reported to affect the expression of $\beta / \gamma$ oscillations in vitro (Treviño et al., 2007).

Previously, we showed that the power and coherence of LFP theta oscillations were differently correlated with the ability of normal and TLE rats to discriminate the temporal and spatial components of recognition memory in an episodic-like memory task (Inostroza et al., 2013). These associations were indicative that the neuronal processes underlying the expression of theta power and coherence might serve different cognitive demands and are distinctly organized in the hippocampus (Sabolek et al., 2009; Hinman et al., 2011; Wells et al., 2013; Long et al., 2014). Theta power is a measure of the amplitude of LFP oscillations controlled by the cholinergic and GABAergic influences of brainstem nuclei (Vertes and Kocsis, 1997; Lee et al., 1994) on hippocampal theta generators (Soltesz and Deschênes, 1993; Hangya et al., 2009; Montgomery et al., 2009). In TLE, the circuit controlling theta power is likely to be impaired as reflected by dampened and slowest hippocampal oscillations (Dugladze et al., 2007; Chauvière et al., 2009; Marcelin et al., 2009; Inostroza et al., 2013; Kitchigina et al., 2013; Cid et al., 2014). Acting through mGluR spared this circuit, since no changes were found in theta power after CPPG in TLE rats but in the theta coherence and timing between entorhinal inputs. Given that theta coherence between hippocampal layers mostly quantifies the consistency of oscillatory phases, our pharmacological and computational interventions give further support to the idea that an appropriate timing between temporoammonic and perforant pathways underlies coordination of multiple theta dipoles in the dorsal hippocampus (Mizuseki et al., 2009; Montgomery et al., 2009; Fernandez et al., 2013). Thus, the proximodistal organization of entorhinal inputs to the dorsal hippocampus is instrumental in temporal lobe memory function and a candidate mechanism to study cognitive comorbidities of TLE.

\section{References}

Aggleton JP, Pearce JM (2001) Neural systems underlying episodic memory: insights from animal research. Philos Trans R Soc Lond B Biol Sci 356:1467-1482. CrossRef Medline

Alonso A, Llinás RR (1989) Subthreshold Na+-dependent theta-like rhythmicity in stellate cells of entorhinal cortex layer II. Nature 342:175-177. CrossRef Medline

Ang CW, Carlson GC, Coulter DA (2006) Massive and specific dysregulation of direct cortical input to the hippocampus in temporal lobe epilepsy. J Neurosci 26:11850-11856. CrossRef Medline

Avoli M, D’Antuono M, Louvel J, Köhling R, Biagini G, Pumain R, D'Arcangelo G, Tancredi V (2002) Network and pharmacological mechanisms leading to epileptiform synchronization in the limbic system in vitro. Prog Neurobiol 68:167-207. CrossRef Medline
Bellistri E, Aguilar J, Brotons-Mas JR, Foffani G, de la Prida LM (2013) Basic properties of somatosensory-evoked responses in the dorsal hippocampus of the rat. J Physiol 591:2667-2686. CrossRef Medline

Benchenane K, Peyrache A, Khamassi M, Tierney PL, Gioanni Y, Battaglia FP, Wiener SI (2010) Coherent theta oscillations and reorganization of spike timing in the hippocampal-prefrontal network upon learning. Neuron 66:921-936. CrossRef Medline

Bland BH, Oddie SD (2001) Theta band oscillation and synchrony in the hippocampal formation and associated structures: the case for its role in sensorimotor integration. Behav Brain Res 127:119-136. CrossRef Medline

Bragin A, Jandó G, Nádasdy Z, van Landeghem M, Buzsáki G (1995) Dentate EEG spikes and associated interneuronal population bursts in the hippocampal hilar region of the rat. J Neurophysiol 73:1691-1705. Medline

Brankack J, Stewart M, Fox SE (1993) Current source density analysis of the hippocampal theta rhythm: associated sustained potentials and candidate synaptic generators. Brain Res 615:310-327. CrossRef Medline

Brun VH, Leutgeb S, Wu HQ, Schwarcz R, Witter MP, Moser EI, Moser MB (2008) Impaired spatial representation in CA1 after lesion of direct input from entorhinal cortex. Neuron 57:290-302. CrossRef Medline

Burgalossi A, Herfst L, von Heimendahl M, Förste H, Haskic K, Schmidt M, Brecht M (2011) Microcircuits of functionally identified neurons in the rat medial entorhinal cortex. Neuron 70:773-786. CrossRef Medline

Burgess N, Maguire EA, O'Keefe J (2002) The human hippocampus and spatial and episodic memory. Neuron 35:625-641. CrossRef Medline

Buzsáki G, Moser EI (2013) Memory, navigation and theta rhythm in the hippocampal-entorhinal system. Nat Neurosci 16:130-138. CrossRef Medline

Chauvière L, Rafrafi N, Thinus-Blanc C, Bartolomei F, Esclapez M, Bernard C (2009) Early deficits in spatial memory and theta rhythm in experimental temporal lobe epilepsy. J Neurosci 29:5402-5410. CrossRef Medline

Cid E, Gomez-Dominguez D, Martin-Lopez D, Gal B, Laurent F, Ibarz JM, Francis F, Menendez de la Prida L (2014) Dampened hippocampal oscillations and enhanced spindle activity in an asymptomatic model of developmental cortical malformations. Front Syst Neurosci 8:50. CrossRef Medline

Cosgrove KE, Meriney SD, Barrionuevo G (2011) High affinity group III mGluRs regulate mossy fiber input to CA3 interneurons. Hippocampus 21:1302-1317. CrossRef Medline

Csicsvari J, Hirase H, Czurkó A, Mamiya A, Buzsáki G (1999) Oscillatory coupling of hippocampal pyramidal cells and interneurons in the behaving rat. J Neurosci 19:274-287. Medline

Deshmukh SS, Knierim JJ (2011) Representation of nonspatial and spatial information in the lateral entorhinal cortex. Front Behav Neurosci 5:69. CrossRef Medline

Deshmukh SS, Yoganarasimha D, Voicu H, Knierim JJ (2010) Theta modulation in the medial and the lateral entorhinal cortices. J Neurophysiol 104:994-1006. CrossRef Medline

Dietrich D, Kral T, Clusmann H, Friedl M, Schramm J (1999) Reduced function of L-AP4-sensitive metabotropic glutamate receptors in human epileptic sclerotic hippocampus. Eur J Neurosci 11:1109-1113. CrossRef Medline

Di Paola M, Macaluso E, Carlesimo GA,Tomaiuolo F, Worsley KJ, Fadda L, Caltagirone C (2007) Episodic memory impairment in patients with Alzheimer's disease is correlated with entorhinal cortex atrophy. J Neurol 254:774-781. CrossRef Medline

Drexel M, Preidt AP, Sperk G (2012) Sequel of spontaneous seizures after kainic acid-induced status epilepticus and associated neuropathological changes in the subiculum and entorhinal cortex. Neuropharmacology 63:806-817. CrossRef Medline

Du F, Eid T, Lothman EW, Köhler C, Schwarcz R (1995) Preferential neuronal loss in layer III of the medial entorhinal cortex in rat models of temporal lobe epilepsy. J Neurosci 15:6301-6313. Medline

Dugladze T, Vida I, Tort AB, Gross A, Otahal J, Heinemann U, Kopell NJ, Gloveli T (2007) Impaired hippocampal rhythmogenesis in a mouse model of mesial temporal lobe epilepsy. Proc Natl Acad Sci U S A 104: 17530-17535. CrossRef Medline

Easton A, Douchamps V, Eacott M, Lever C (2012) A specific role for septohippocampal acetylcholine in memory? Neuropsychologia 50:31563168. CrossRef Medline

Eichenbaum H, Dudchenko P, Wood E, Shapiro M, Tanila H (1999) The 
hippocampus, memory, and place cells: is it spatial memory or a memory space? Neuron 23:209-226. CrossRef Medline

Evans DI, Jones RS, Woodhall G (2000) Activation of presynaptic group III metabotropic receptors enhances glutamate release in rat entorhinal cortex. J Neurophysiol 83:2519-2525. Medline

Fernandez FR, Malerba P, Bressloff PC, White JA (2013) Entorhinal stellate cells show preferred spike phase-locking to theta inputs that is enhanced by correlations in synaptic activity. J Neurosci 33:6027-6040. CrossRef Medline

Ferraguti F, Klausberger T, Cobden P, Baude A, Roberts JD, Szucs P, Kinoshita A, Shigemoto R, Somogyi P, Dalezios Y (2005) Metabotropic glutamate receptor 8-expressing nerve terminals target subsets of GABAergic neurons in the hippocampus. J Neurosci 25:10520-10536. CrossRef Medline

Franaszczuk PJ, Blinowska KJ, Kowalczyk M (1985) The application of parametric multichannel spectral estimates in the study of electrical brain activity. Biol Cybern 51:239-247. CrossRef Medline

Frank LM, Brown EN, Wilson M (2000) Trajectory encoding in the hippocampus and entorhinal cortex. Neuron 27:169-178. CrossRef Medline

Giocomo LM, Hasselmo ME (2008) Time constants of h current in layer ii stellate cells differ along the dorsal to ventral axis of medial entorhinal cortex. J Neurosci 28:9414-9425. CrossRef Medline

Gómez-Isla T, Price JL, McKeel DW Jr, Morris JC, Growdon JH, Hyman BT (1996) Profound loss of layer II entorhinal cortex neurons occurs in very mild Alzheimer's disease. J Neurosci 16:4491-4500. Medline

Gupta AS, van der Meer MA, Touretzky DS, Redish AD (2012) Segmentation of spatial experience by hippocampal theta sequences. Nat Neurosci 15:1032-1039. CrossRef Medline

Hales JB, Schlesiger MI, Leutgeb JK, Squire LR, Leutgeb S, Clark RE (2014) Medial entorhinal cortex lesions only partially disrupt hippocampal place cells and hippocampus-dependent place memory. Cell Rep 9:893-901. CrossRef Medline

Hangya B, Borhegyi Z, Szilágyi N, Freund TF, Varga V (2009) GABAergic neurons of the medial septum lead the hippocampal network during theta activity. J Neurosci 29:8094-8102. CrossRef Medline

Hargreaves EL, Rao G, Lee I, Knierim JJ (2005) Major dissociation between medial and lateral entorhinal input to dorsal hippocampus. Science 308: 1792-1794. CrossRef Medline

Hartzell AL, Burke SN, Hoang LT, Lister JP, Rodriguez CN, Barnes CA (2013) Transcription of the immediate-early gene Arc in CA1 of the hippocampus reveals activity differences along the proximodistal axis that are attenuated by advanced age. J Neurosci 33:3424-3433. CrossRef Medline

Hasselmo ME, Bodelón C, Wyble BP (2002) A proposed function for hippocampal theta rhythm: separate phases of encoding and retrieval enhance reversal of prior learning. Neural Comput 14:793-817. CrossRef Medline

Helmstaedter C (2002) Effects of chronic epilepsy on declarative memory systems. Prog Brain Res 135:439-453. CrossRef Medline

Henriksen EJ, Colgin LL, Barnes CA, Witter MP, Moser MB, Moser EI (2010) Spatial representation along the proximodistal axis of CA1. Neuron 68:127-137. CrossRef Medline

Hinman JR, Penley SC, Long LL, Escabí MA, Chrobak JJ (2011) Septotemporal variation in dynamics of theta: speed and habituation. J Neurophysiol 105:2675-2686. CrossRef Medline

Huang Z, Walker MC, Shah MM (2009) Loss of dendritic HCN1 subunits enhances cortical excitability and epileptogenesis. J Neurosci 29:1097910988. CrossRef Medline

Huxter JR, Senior TJ, Allen K, Csicsvari J (2008) Theta phase-specific codes for two-dimensional position, trajectory and heading in the hippocampus. Nat Neurosci 11:587-594. CrossRef Medline

Igarashi KM, Lu L, Colgin LL, Moser MB, Moser EI (2014) Coordination of entorhinal-hippocampal ensemble activity during associative learning. Nature 510:143-147. CrossRef Medline

Inostroza M, Cid E, Brotons-Mas J, Gal B, Aivar P, Uzcategui YG, Sandi C, Menendez de la Prida L (2011) Hippocampal-dependent spatial memory in the water maze is preserved in an experimental model of temporal lobe epilepsy in rats. PLoS One 6:e22372. CrossRef Medline

Inostroza M, Brotons-Mas JR, Laurent F, Cid E, Menendez de la Prida LM (2013) Specific impairment of "What-Where-When" episodic-like memory in experimental models of temporal lobe epilepsy. J Neurosci 33:17749-17762. CrossRef Medline
Jarsky T, Mady R, Kennedy B, Spruston N (2008) Distribution of bursting neurons in the CAl region and the subiculum of the rat hippocampus. J Comp Neurol 506:535-547. CrossRef Medline

Kitamura T, Pignatelli M, Suh J, Kohara K, Yoshiki A, Abe K, Tonegawa S (2014) Island cells control temporal association memory. Science 343: 896-901. CrossRef Medline

Kitchigina V, Popova I, Sinelnikova V, Malkov A, Astasheva E, Shubina L, Aliev R (2013) Disturbances of septohippocampal theta oscillations in the epileptic brain: reasons and consequences. Exp Neurol 247:314-327. CrossRef Medline

Klapstein GJ, Meldrum BS, Mody I (1999) Decreased sensitivity to Group III mGluR agonists in the lateral perforant path following kindling. Neuropharmacology 38:927-933. CrossRef Medline

Kloosterman F, Van Haeften T, Witter MP, Lopes Da Silva FH (2003) Electrophysiological characterization of interlaminar entorhinal connections: an essential link for re-entrance in the hippocampal-entorhinal system. Eur J Neurosci 18:3037-3052. CrossRef Medline

Kobayashi M, Wen X, Buckmaster PS (2003) Reduced inhibition and increased output of layer II neurons in the medial entorhinal cortex in a model of temporal lobe epilepsy. J Neurosci 23:8471-8479. Medline

Kohara K, Pignatelli M, Rivest AJ, Jung HY, Kitamura T, Suh J, Frank D, Kajikawa K, Mise N, Obata Y, Wickersham IR, Tonegawa S (2014) Cell type-specific genetic and optogenetic tools reveal hippocampal CA2 circuits. Nat Neurosci 17:269-279. CrossRef Medline

Komorowski RW, Manns JR, Eichenbaum H (2009) Robust conjunctive item-place coding by hippocampal neurons parallels learning what happens where. J Neurosci 29:9918-9929. CrossRef Medline

Kral T, Erdmann E, Sochivko D, Clusmann H, Schramm J, Dietrich D (2003) Down-regulation of mGluR8 in pilocarpine epileptic rats. Synapse 47: 278-284. CrossRef Medline

Kraus BJ, Robinson RJ 2nd, White JA, Eichenbaum H, Hasselmo ME (2013) Hippocampal "time cells": time versus path integration. Neuron 78: 1090-1101. CrossRef Medline

Kumar SS, Buckmaster PS (2006) Hyperexcitability, interneurons, and loss of GABAergic synapses in entorhinal cortex in a model of temporal lobe epilepsy. J Neurosci 26:4613-4623. CrossRef Medline

Kumar SS, Jin X, Buckmaster PS, Huguenard JR (2007) Recurrent circuits in layer II of medial entorhinal cortex in a model of temporal lobe epilepsy. J Neurosci 27:1239-1246. CrossRef Medline

Lee MG, Chrobak JJ, Sik A, Wiley RG, Buzsáki G (1994) Hippocampal theta activity following selective lesion of the septal cholinergic system. Neuroscience 62:1033-1047. CrossRef Medline

Lenck-Santini PP, Holmes GL (2008) Altered phase precession and compression of temporal sequences by place cells in epileptic rats. J Neurosci 28:5053-5062. CrossRef Medline

Lisman JE, Jensen O (2013) The theta-gamma neural code. Neuron 77: 1002-1016. CrossRef Medline

Long LL, Hinman JR, Chen CM, Escabi MA, Chrobak JJ (2014) Theta dynamics in rat: speed and acceleration across the Septotemporal axis. PLoS One 9:e97987. CrossRef Medline

Macek TA, Winder DG, Gereau RW 4th, Ladd CO, Conn PJ (1996) Differential involvement of group II and group III mGluRs as autoreceptors at lateral and medial perforant path synapses. J Neurophysiol 76:37983806. Medline

Maguire EA, Frith CD (2003) Aging affects the engagement of the hippocampus during autobiographical memory retrieval. Brain 126:15111523. CrossRef Medline

Mankin EA, Sparks FT, Slayyeh B, Sutherland RJ, Leutgeb S, Leutgeb JK (2012) Neuronal code for extended time in the hippocampus. Proc Natl Acad Sci U S A 109:19462-19467. CrossRef Medline

Marcelin B, Chauvière L, Becker A, Migliore M, Esclapez M, Bernard C (2009) h channel-dependent deficit of theta oscillation resonance and phase shift in temporal lobe epilepsy. Neurobiol Dis 33:436-447. CrossRef Medline

Masukawa LM, Benardo LS, Prince DA (1982) Variations in electrophysiological properties of hippocampal neurons in different subfields. Brain Res 242:341-344. CrossRef Medline

Mercier MS, Lodge D, Fang G, Nicolas CS, Collett VJ, Jane DE, Collingridge GL, Bortolotto ZA (2013) Characterisation of an mGlu8 receptorselective agonist and antagonist in the lateral and medial perforant path inputs to the dentate gyrus. Neuropharmacology 67:294-303. CrossRef Medline 
Mitzdorf U (1985) Current source-density method and application in cat cerebral cortex: investigation of evoked potentials and EEG phenomena. Physiol Rev 65:37-100. Medline

Mizuseki K, Sirota A, Pastalkova E, Buzsáki G (2009) Theta oscillations provide temporal windows for local circuit computation in the entorhinalhippocampal loop. Neuron 64:267-280. CrossRef Medline

Montgomery SM, Betancur MI, Buzsáki G (2009) Behavior-dependent coordination of multiple theta dipoles in the hippocampus. J Neurosci 29: 1381-1394. CrossRef Medline

Naber PA, Lopes da Silva FH, Witter MP (2001) Reciprocal connections between the entorhinal cortex and hippocampal fields $\mathrm{CA} 1$ and the subiculum are in register with the projections from CA1 to the subiculum. Hippocampus 11:99-104. CrossRef Medline

Nakamura NH, Flasbeck V, Maingret N, Kitsukawa T, Sauvage MM (2013) Proximodistal segregation of nonspatial information in CA3: preferential recruitment of a proximal CA3-distal CA1 network in nonspatial recognition memory. J Neurosci 33:11506-11514. CrossRef Medline

Neunuebel JP, Knierim JJ (2012) Spatial firing correlates of physiologically distinct cell types of the rat dentate gyrus. J Neurosci 32:3848-3858. CrossRef Medline

Nishimura-Akiyoshi S, Niimi K, Nakashiba T, Itohara S (2007) Axonal netrin-Gs transneuronally determine lamina-specific subdendritic segments. Proc Natl Acad Sci U S A 104:14801-14806. CrossRef Medline

O'Keefe J, Nadel L (1978) The hippocampus as a cognitive map. Oxford, UK: Oxford UP.

Parent JM, Yu TW, Leibowitz RT, Geschwind DH, Sloviter RS, Lowenstein DH (1997) Dentate granule cell neurogenesis is increased by seizures and contributes to aberrant network reorganization in the adult rat hippocampus. J Neurosci 17:3727-3738. Medline

Paxinos G, Watson C (2005) The rat brain in stereotaxic coordinates, 5th ed. London: Elsevier.

Peng Z, Zhang N, Wei W, Huang CS, Cetina Y, Otis TS, Houser CR (2013) A reorganized GABAergic circuit in a model of epilepsy: evidence from optogenetic labeling and stimulation of somatostatin interneurons. J Neurosci 33:14392-14405. CrossRef Medline

Penley SC, Hinman JR, Long LL, Markus EJ, Escabí MA, Chrobak JJ (2013) Novel space alters theta and gamma synchrony across the longitudinal axis of the hippocampus. Front Syst Neurosci 7:20. CrossRef Medline

Pettersen KH, Devor A, Ulbert I, Dale AM, Einevoll GT (2006) Currentsource density estimation based on inversion of electrostatic forward solution: effects of finite extent of neuronal activity and conductivity discontinuities. J Neurosci Methods 154:116-133. CrossRef Medline

Poncer JC, Shinozaki H, Miles R (1995) Dual modulation of synaptic inhibition by distinct metabotropic glutamate receptors in the rat hippocampus. J Physiol 485:121-134. CrossRef Medline

Quilichini P, Sirota A, Buzsáki G (2010) Intrinsic circuit organization and theta-gamma oscillation dynamics in the entorhinal cortex of the rat. J Neurosci 30:11128-11142. CrossRef Medline

Ray S, Naumann R, Burgalossi A, Tang Q, Schmidt H, Brecht M (2014) Grid-layout and theta-modulation of layer 2 pyramidal neurons in medial entorhinal cortex. Science 343:891-896. CrossRef Medline

Sabolek HR, Penley SC, Hinman JR, Bunce JG, Markus EJ, Escabi M, Chrobak JJ (2009) Theta and gamma coherence along the septotemporal axis of the hippocampus. J Neurophysiol 101:1192-1200. CrossRef Medline

Sargolini F, Fyhn M, Hafting T, McNaughton BL, Witter MP, Moser MB, Moser EI (2006) Conjunctive representation of position, direction, and velocity in entorhinal cortex. Science 312:758-762. CrossRef Medline

Scharfman HE (1991) Dentate hilar cells with dendrites in the molecular layer have lower thresholds for synaptic activation by perforant path than granule cells. J Neurosci 11:1660-1673. Medline

Scharfman HE, Sollas AE, Berger RE, Goodman JH, PierceJP (2003) Perforant path activation of ectopic granule cells that are born after pilocarpine-induced seizures. Neuroscience 121:1017-1029. CrossRef Medline

Schwarcz R, Witter MP (2002) Memory impairment in temporal lobe epilepsy: the role of entorhinal lesions. Epilepsy Res 50:161-177. CrossRef Medline
Semyanov A, Kullmann DM (2000) Modulation of GABAergic signaling among interneurons by metabotropic glutamate receptors. Neuron 25: 663-672. CrossRef Medline

Shigemoto R, Kinoshita A, Wada E, Nomura S, Ohishi H, Takada M, Flor PJ, Neki A, Abe T, Nakanishi S, Mizuno N (1997) Differential presynaptic localization of metabotropic glutamate receptor subtypes in the rat hippocampus. J Neurosci 17:7503-7522. Medline

Sloviter RS, Argyle VB, Schwarcz R, Frotscher M (2012) Abnormal dentate gyrus network circuitry in temporal lobe epilepsy. In Jasper's basic mechanisms of the epilepsies, Ed 4 (Noebels JL, Avoli M, Rogawski MA, Olsen RW, Delgado-Escueta AV, eds). Bethesda, MD: National Center for Biotechnology Information.

Soltesz I, Deschênes M (1993) Low- and high-frequency membrane potential oscillations during theta activity in CA1 and CA3 pyramidal neurons of the rat hippocampus under ketamine-xylazine anesthesia. J Neurophysiol 70:97-116. Medline

Suh J, Rivest AJ, Nakashiba T, Tominaga T, Tonegawa S (2011) Entorhinal cortex layer III input to the hippocampus is crucial for temporal association memory. Science 334:1415-1420. CrossRef Medline

Tahvildari B, Alonso A (2005) Morphological and electrophysiological properties of lateral entorhinal cortex layers II and III principal neurons. J Comp Neurol 491:123-140. CrossRef Medline

Tamamaki N, Nojyo Y (1995) Preservation of topography in the connections between the subiculum, field $\mathrm{CA} 1$, and the entorhinal cortex in rats. J Comp Neurol 353:379-390. CrossRef Medline

Tolner EA, Frahm C, Metzger R, Gorter JA, Witte OW, Lopes da Silva FH, Heinemann U (2007) Synaptic responses in superficial layers of medial entorhinal cortex from rats with kainate-induced epilepsy. Neurobiol Dis 26:419-438. CrossRef Medline

Tort AB, Komorowski RW, Manns JR, Kopell NJ, Eichenbaum H (2009) Theta-gamma coupling increases during the learning of item-context associations. Proc Natl Acad Sci U S A 106:20942-20947. CrossRef Medline

Treviño M, Vivar C, Gutiérrez R (2007) Beta/gamma oscillatory activity in the CA3 hippocampal area is depressed by aberrant GABAergic transmission from the dentate gyrus after seizures. J Neurosci 27:251-259. CrossRef Medline

Vertes RP, Kocsis B (1997) Brainstem-diencephalo-septohippocampal systems controlling the theta rhythm of the hippocampus. Neuroscience 81:893-926. CrossRef Medline

Wells CE, Amos DP, Jeewajee A, Douchamps V, Rodgers J, O'Keefe J, Burgess N, Lever C (2013) Novelty and anxiolytic drugs dissociate two components of hippocampal theta in behaving rats. J Neurosci 33:8650-8667. CrossRef Medline

Witter MP (2007) The perforant path: projections from the entorhinal cortex to the dentate gyrus. Prog Brain Res 163:43-61. CrossRef Medline

Witter MP, Moser EI (2006) Spatial representation and the architecture of the entorhinal cortex. Trends Neurosci 29:671-678. CrossRef Medline

Witter MP, Naber PA, van Haeften T, Machielsen WC, Rombouts SA, Barkhof F, Scheltens P, Lopes da Silva FH (2000) Cortico-hippocampal communication by way of parallel parahippocampal-subicular pathways. Hippocampus 10:398-410. CrossRef Medline

Wood ER, Dudchenko PA, Robitsek RJ, Eichenbaum H (2000) Hippocampal neurons encode information about different types of memory episodes occurring in the same location. Neuron 27:623-633. CrossRef Medline

Wyble BP, Hyman JM, Rossi CA, Hasselmo ME (2004) Analysis of theta power in hippocampal EEG during bar pressing and running behavior in rats during distinct behavioral contexts. Hippocampus 14:662-674. CrossRef Medline

Ylinen A, Bragin A, Nádasdy Z, Jandó G, Szabó I, Sik A, Buzsáki G (1995) Sharp wave-associated high-frequency oscillation $(200 \mathrm{~Hz})$ in the intact hippocampus: network and intracellular mechanisms. J Neurosci 15:3046. Medline

Young BJ, Otto T, Fox GD, Eichenbaum H (1997) Memory representation within the parahippocampal region. J Neurosci 17:5183-5195. Medline 